\title{
Can Mur (Barcelona). Crisoles con sistema de prensión y la metalurgia de la Edad del Bronce en el nordeste de la Península Ibérica
}

\author{
Can Mur (Barcelona province). Prehension-system crucibles and Bronze Age metallurgy in \\ Northeast Iberia
}

Ignacio Soriano $^{\mathrm{a}}$ y Nicolau Escanilla ${ }^{\mathrm{b}}$

\section{RESUMEN}

Este artículo da a conocer un crisol con pie macizo inédito procedente del asentamiento de la Edad del Bronce de Can Mur (Valldoreix, Barcelona). Se describen sus características tipológicas y se aportan datos composicionales de las adherencias de base cobre (FRXp). Se exponen los crisoles sincrónicos con sistema de prensión existentes en la Península Ibérica y, tras detallar los paralelos en el Próximo Oriente y Europa, se propone su llegada a través del Mediterráneo Occidental vinculados a otras innovaciones metalúrgicas. Finalmente se detallan las características principales de la metalurgia de la Edad del Bronce en el nordeste de la Península Ibérica. Se hace especial hincapié en la innovación tecnológica, estructuración de la producción y circulación de materiales entre regiones.
North-Eastern Iberian Peninsula are set forth. Special emphasis is placed on technological innovation, the organization of production and the circulation of materials between different regions.

Palabras clave: Metalurgia prehistórica; Crisol con perforación para el enmangue; Crisol con pie macizo; FRXp; Difusión tecnológica; Prehistoria Reciente; Mediterráneo Occidental.

Key words: Prehistoric metallurgy; Socketed crucible; Pedestal base crucible; $p X R F$; Technological diffusion; Late Prehistory; Western Mediterranean.

\section{INTRODUCCIÓN}

\begin{abstract}
We publish a new pedestal-base crucible from the Early Bronze Age settlement of Can Mur (Valldoreix, Barcelona province). Its typological characteristics are described and the chemical composition ( $p X R F)$ data of the copper residues are provided. Contemporaneous crucibles with hafting system from the Iberian Peninsula are discussed. The parallels existing in the Middle East and Europe suggest that they arrived in the Western Mediterranean linked to other metallurgical innovations. Lastly the main features of the metallurgy of the Bronze Age in
\end{abstract}

El objetivo principal de este trabajo es dar a conocer un útil metalúrgico excepcional que ha permanecido inédito durante más de 40 años y exponer los objetos similares documentados en el nordeste. Se trata de un crisol con pie macizo, uno de los escasos existentes en la Península Ibérica, localizado de forma fortuita en un yacimiento del Bronce Inicial (Bronce Antiguo-Medio, c. 23001200 cal BC). Lo hemos denominado Can Mur, en reconocimiento al actual depositario de los

a Grupo de Investigación Arqueológica del Nordeste Peninsular (GRANEP) y Dpto. de Historia, Universitat de Lleida. Plaza Víctor Siurana 1.25003 Lleida. España. Correo e.: nachsoriano@hotmail.com

b Grupo de Investigación Arqueoecología Social Mediterránea (ASOME). Dpto. de Prehistòria, Universitat Autònoma de Barcelona. Campus de Bellaterra. 08193 Barcelona. España. Correo e.: nescanilla@gmail.com

Recibido 20-VII-2015; aceptado 6-X-2015. 


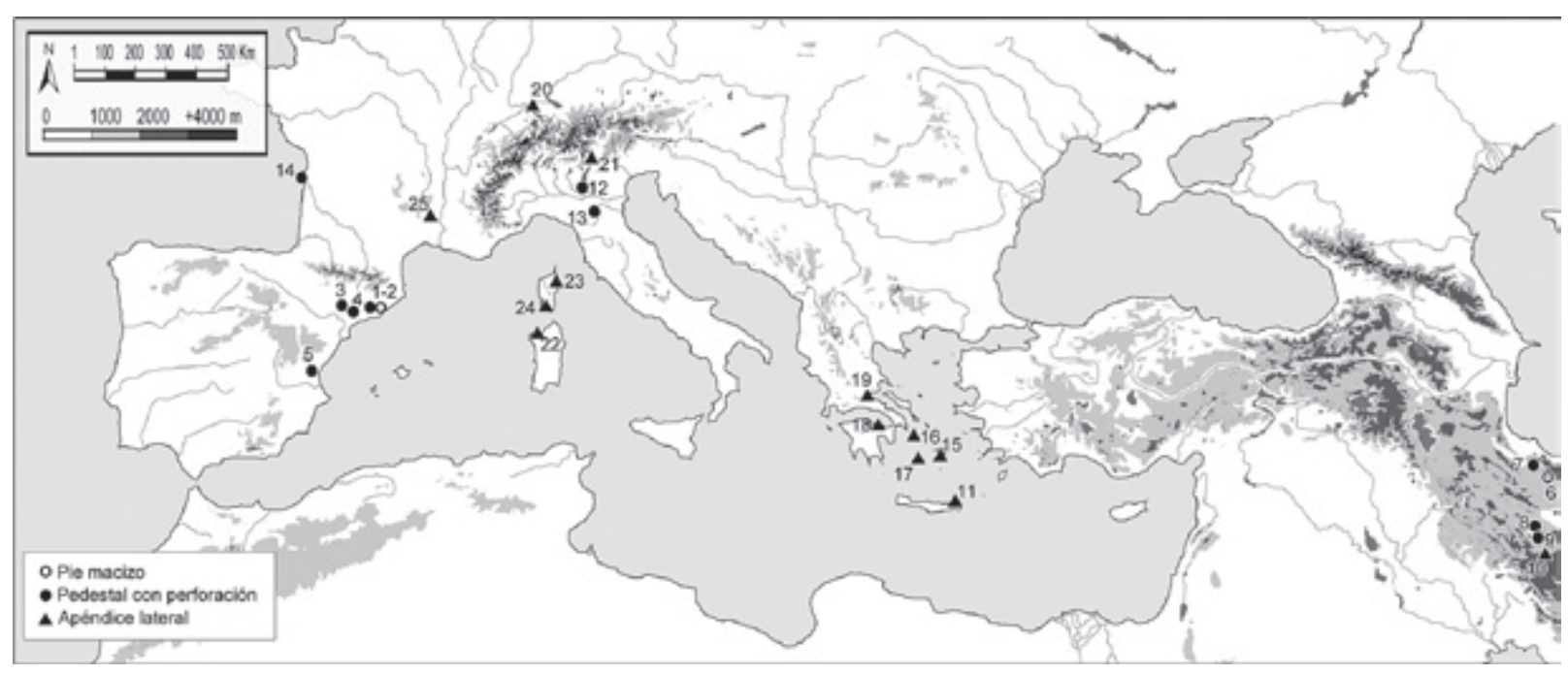

Fig. 1. Localización de yacimientos con crisoles con sistema de prensión, según el grupo en el que se clasifican y enumeración en el texto: 1. Can Mur (Valldoreix) y 2. Can Roqueta II (Sabadell), Barcelona; 3. Minferri (Juneda) y 4. Cantorella (Maldà), Lleida; 5. Peña la Dueña (Teresa, Castellón); 6, 7, 8, 9 y 10. Cheshmeh Ali (Teherán), Tepe Ghabristan (Gazvin), Arisman y Tepe Sialk (Kashan) y Qaleh Gusheh (Natanz); 11. Aghia Photia (Siteia, Creta); 12 y 13. Castellaro del Vhò (Piadena, Cremona) y Montale (Castelnuovo Rangone, Módena); 14. Lède du Gurp (Grayan-etl'Hôpital, Aquitania); 15, 16, 17, 18 y 19. Kastri (Syros), Kephala (Ceos), Phylkopi (Melos), islas Cícladas, Lerne IV (Argólida) y Sesklo (Tesalia); 20. Mozartstrasse (Zurich); 21. Lago di Ledro y Fiavé (Trento, Tentino-Alto Adigio) y 22. Monte d'Accodi (Sassari, Cerdeña); 23, 24 y 25. Terrina IV (Aléria) y Alo-Bisughjè (Bilia), Córcega; Beaussement (Ardèche, Rhône-Alpes).

materiales, D. Andreu Mur, quien nos comunicó su existencia y facilitó este estudio.

Paralelamente a la descripción y análisis de la pieza, hemos considerado fundamental recoger el resto de crisoles de la Península Ibérica con sistema de prensión, dada la singularidad de los mismos. Nuestro interés no radica en establecer un catálogo definitivo de estos útiles sino en interpretarlos en el contexto de la metalurgia del Bronce Inicial en el nordeste de la Península Ibérica $y$, en concreto, en valorarlos dentro de un período de intensas relaciones y contactos con otros grupos del Occidente europeo.

\section{EL YACIMIENTO DE CAN MUR}

\subsection{Situación geográfica e historia del hallazgo}

Can Mur se localiza en el núm. 35-37 de la calle Moreneta de Montserrat, en el barrio de la Colonia Montserrat (Valldoreix, Vallès Occidental, Barcelona), justo en el límite administrativo con el término municipal del Papiol (Baix Llobregat, Barcelona $)^{1}$. Esta zona se ubica en el sector noroeste del Parque Natural de la Sierra de Collserola, al sur de la Serralada Litoral catalana (Fig. 1). Geológicamente dicha sierra está formada en su mayoría por rocas metamórficas (esquistos, pizarras) asentadas sobre un zócalo granítico. En las cercanías del yacimiento hay abundantes recursos hídricos (Torrent d'En Llobet, Torrent de Can Badal, Torrent de les Flors, Torrent de la Rierada).

En el año 1972 se acondicionó el jardín de la vivienda situada en dicha dirección ${ }^{2}$, rebajando más de un metro de tierra para dividir la antigua propiedad en dos parcelas. El resultado fue la aparición de materiales arqueológicos en una tierra de aspecto ceniciento. Entre ellos abundaban los restos óseos (desconocemos si humanos o faunísticos) y cerámicos. Desgraciadamente el

\footnotetext{
${ }^{1}$ Coordenadas UTM(ED50) 31T 420643, 4588664; 215 metros s.n.m.

2 D. Andreu Mur, hijo del antiguo propietario de la finca, nos relató la historia del hallazgo que presenció a la edad de 10 años.
} 
albañil ejecutor de los trabajos rompió todos los materiales, crisol incluido. Los que presentamos en este estudio son los únicos conservados. El yacimiento nunca fue documentado ni cuenta con más datos que los aludidos ${ }^{3}$. Casi de inmediato tras su descubrimiento se tapó el rebaje con el mismo sedimento extraído, edificando sobre él un muro de delimitación de las parcelas, que se conserva en la actualidad.

\subsection{Materiales y cronología relativa}

La colección se limita a cinco fragmentos de cerámica correspondientes a varios contenedores (Fig. 2.1 a 4), un molino de tipo barquiforme (Fig. 2.5) y el crisol del que nos ocupamos más adelante. La cerámica concuerda con la genérica del Bronce Inicial. La hemos descrito siguiendo a Petit ${ }^{4}$, indicando entre paréntesis los paralelos según su propuesta tipológica:

1. Lengüeta horizontal plana ancha (Fig. 2.1). Superficie alisada, cocción oxidante al exterior y reductora al interior. Corresponde a un gran contenedor del tipo urna de fondo plano ( $\mathrm{n}^{\mathrm{o}} 44,45,48$ o 49 del Bronce Antiguo) o a un vaso troncocónico $\left(\mathrm{n}^{\mathrm{o}} 20 \mathrm{del}\right.$ Bronce Medio).

2. Lengüeta horizontal plana estrecha con inicio de labio exvasado (Fig. 2.2). Superficie alisada, cocción oxidante al exterior y reductora al interior. Vaso subtroncocónico o gran contenedor del tipo urna de fondo plano ( $\mathrm{n}^{\circ} 25$ y 48 del Bronce Antiguo).

3. Pezón circular sobre carena (Fig. 2.3). Superficie bruñida y cocción reductora. Vaso carenado de $14 \mathrm{~cm}$ de diámetro máximo, con fondo umbilicado $\left(\mathrm{n}^{\mathrm{o}} 34\right.$ del Bronce Antiguo) o convexo ( $\mathrm{n}^{\circ} 23$ del Bronce Medio).

${ }^{3}$ Generalitat de Catalunya. Departament de Cultura. Inventari del Patrimoni Cultural Immoble de Catalunya: Arqueològic: Vallès Occidental, Baix Llobregat [en línea]. Generalitat de Catalunya. Departament de Cultura. Barcelona. https://extranet. cultura.gencat.cat/EGIPCI/login.aspx (consulta 24-II-2015).

${ }^{4}$ Petit, M. ${ }^{a}$ A. 1986: Contribución al estudio de la Edad del Bronce en Cataluña (comarcas de El Moianès, Vallès Oriental, Vallès Occidental, Barcelonès, Maresme y Baix Llobregat). Tesis Doctoral inédita, Universidad Autónoma de Barcelona. Bellaterra: $1559-1732$.
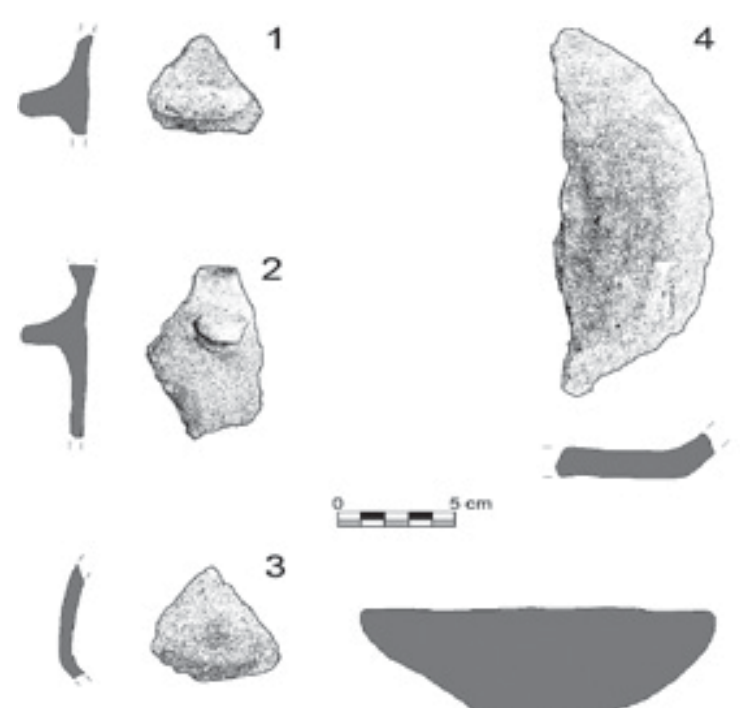

3
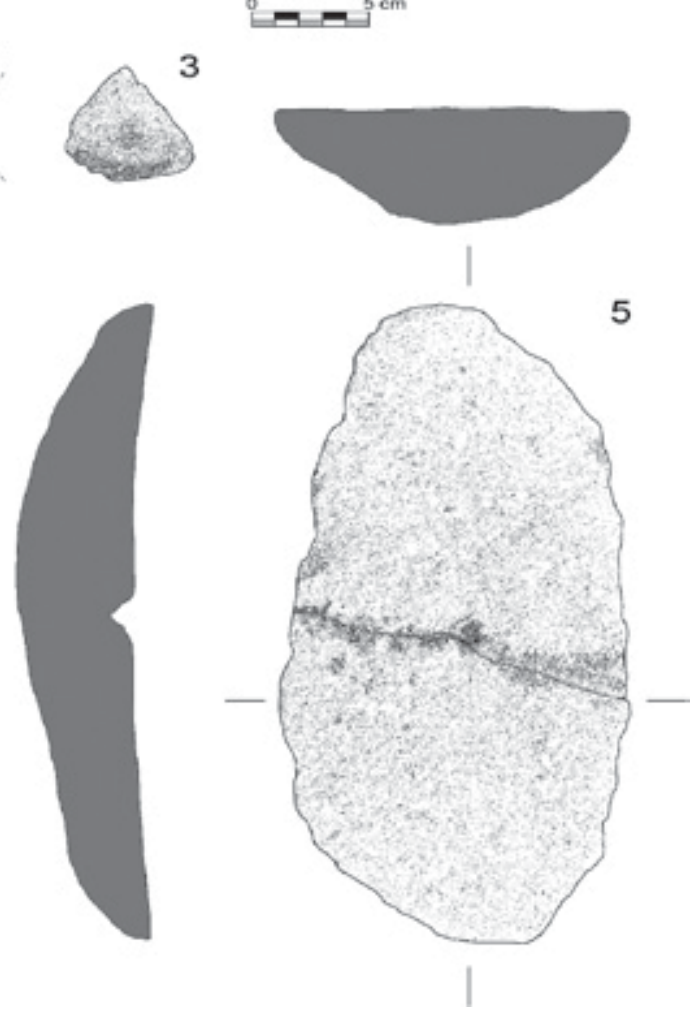

Fig. 2. Contenedores cerámicos (1-4) de Can Mur, según su enumeración en el texto: 1. Lengüeta horizontal plana ancha; 2. Lengüeta horizontal plana estrecha con inicio de labio exvasado; 3. Pezón circular sobre carena; 4. Base planta; 5. Molino barquiforme (dibujos Emiliano Hinojo).

4. Base plana (Fig. 2.4). Superficie alisada y cocción reductora. Tiene $14 \mathrm{~cm}$ de diámetro. Gran contenedor bien del tipo urna de fondo plano ( ${ }^{\circ} 44$ y 49 del Bronce Antiguo y 14 del Bronce Medio), vaso de perfil en " $\mathrm{S}$ " ( $\mathrm{n}^{\circ}$ 52 a 54 del Bronce Antiguo y 37 del Bronce Medio) o vaso de provisiones $\left(n^{\circ} 55,57\right.$ y 58 del Bronce Antiguo y 35 del Bronce Medio). 
5. Fragmento informe. Superficie alisada y cocción reductora. Tipo cerámico indeterminado.

Las formas cerámicas enumeradas están ampliamente documentadas en otros yacimientos del Bronce Inicial, en su gran mayoría asentamientos agrícolas en llanura del tipo "agrupación de fosas". No conocemos ningún estudio que haya relacionado los tipos cerámicos con las fechas C14 disponibles, para discernir la vigencia de cada uno de ellos. Por ello nos es imposible precisar más la cronología de los materiales cerámicos de Can Mur. Creemos que proceden de una estructura negativa amortizada, quizás un silo de almacenamiento o un fondo de cabaña, perteneciente a un asentamiento del tipo "agrupación de fosas".

\section{EL CRISOL. DESCRIPCIÓN Y CARACTERÍSTICAS}

El crisol presenta tendencia hemisférica, ancho pie circular de base plana y pico vertedero (Fig. 3). La cerámica, de cocción oxidante, está ennegrecida debido a su uso metalúrgico y fue restaurada de forma no profesional empleando adhesivo epoxy (Araldit) para unir los diferentes fragmentos así como cemento para restituir las partes no conservadas. Sus dimensiones (en mm) son 141 de long., 113 de anch. exterior y 80 interior, 71 de alt. y $150 \mathrm{cc}$. aprox. de capacidad. El pico vertedero es ligeramente oblicuo con el fin de mejorar la precisión del vertido. El espesor de las paredes va aumentando conforme se acerca al fondo, con el objetivo de favorecer la resistencia ante las altas temperaturas.

La funcionalidad de esta pieza como crisol está atestiguada por la presencia de pequeños restos de óxido de cobre en el pico vertedero (Fig. 3B) así como la evidente termoalteración de toda su superficie. Además la morfología de la pieza, con piquera y sistema de prehensión, no deja lugar a dudas. La primera es esencial para facilitar el vertido del metal en el molde mientras que el segundo mejora sensiblemente la manipulación del crisol. Ambos elementos son específicos de este tipo de útiles y están ausentes en las vasijas de reducción debido a su propio funcionamiento. Sin embargo no se trata de características documen- tadas en todos los crisoles. A título de ejemplo en la Península Ibérica algunos crisoles contemporáneos del Sudeste presentan únicamente pico vertedero, mientras que los documentados en el Valle del Ebro y Levante carecen de ambos elementos (Montero 1999: 344-345; Rodríguez de la Esperanza 2005: 61-63). En el ejemplar de Can Mur el pie funcionaría como agarradero en el que afianzar el dispositivo empleado como mango. Siguiendo ejemplos arqueológicos, etnográficos y experimentales, podrían haberse usado dos varillas de madera verde, previamente mojadas, a modo de pinzas. Éstas deberían ser sostenidas entre dos personas, cruzándolas entre sí y quedando el crisol aprisionado en el centro, tal y como muestra el fresco egipcio de la Tumba de Rekhmire (Tebas, Imperio Nuevo, c. 1500 cal BC) (Garenne-Marot 1985: 86). Otro método potencial consistiría en la torsión en forma de "U" de ciertas especies vegetales para atenazar el crisol, de manera similar al enmangue empleado en los picos de minero (Coghlan 1975: 97-98). Los datos experimentales han demostrado que la temperatura alcanzada por el crisol en su parte externa sería algunos centenares de grados menor que la interna, lo que posibilitaría los sistemas descritos para su manipulación (Freestone 1989: 157). Tampoco sería descartable el recubrimiento con arcilla de dichos elementos vegetales (Tylecote 1976: 18).

Con el objetivo de corroborar la funcionalidad propuesta así como obtener datos de la colada metálica se ha analizado la composición química en varios puntos de la pieza. La técnica empleada ha sido la espectrometría portátil de fluorescencia de rayos X (FRXp), mediante un espectrómetro INNOV-X Alpha equipado con tubo de rayos $\mathrm{X}$ instalado en el Museo Arqueológico Nacional (Madrid). Los tiempos de adquisición se fijaron en 40 ss y los valores cuantitativos fueron calculados a partir de patrones certificados. Los puntos de análisis corresponden tanto a áreas con restos visibles de metal o que pudieron entrar en contacto con el mismo (bordes, piquera) como a zonas que, teóricamente, no lo hicieron (base del pie).

Los resultados obtenidos, aunque no pueden considerarse concluyentes, muestran una proporción de cobre ligeramente mayor en las primeras áreas en detrimento de la segunda, ausencia de estaño y presencia de hierro, este último vinculado a la composición de la pasta cerámica (Tab. 1). Sin embargo no podemos establecer si el metal 

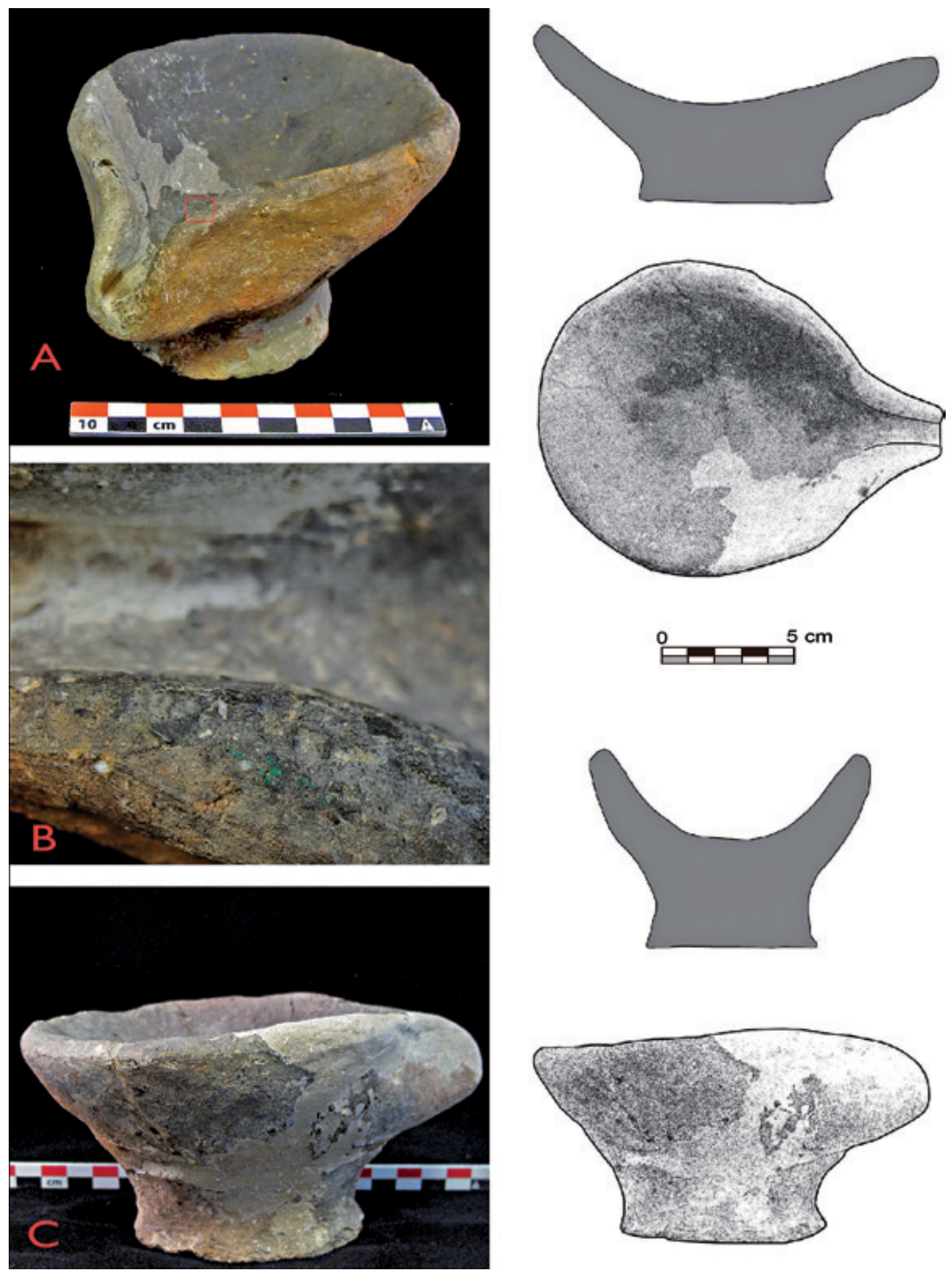

Fig. 3. Crisol con sistema de prensión de Can Mur y (B) detalle de restos de óxido de cobre en uno de los bordes (fotografías Nicolau Escanilla; dibujos Emiliano Hinojo).

Trab. Prehist., 73, N. ${ }^{\circ}$ 1, enero-junio 2016, pp. 160-179, ISSN: 0082-5638 doi: $10.3989 /$ tp.2016.12169 
fundido fue cobre puro o bronce. Los experimentos realizados con crisoles y moldes indican que la proporción de los elementos detectados puede diferir sensiblemente de la colada original, de manera que los resultados deben interpretarse con cautela (Dungworth 2000: 85; Kearns et al. 2010: 55). El estaño deja pocos restos, a veces cercanos al límite de detección, incluso en las coladas de bronce más ricas. El cobre, en cambio, se detecta con claridad aunque muy a menudo en una proporción menor a la original. Los datos actuales sobre la metalurgia del Bronce Inicial en el nordeste indican que el bronce constituye la aleación más comúnmente empleada. Ésta se usa de forma exclusiva en hachas de rebordes, puñales de remaches, puntas de flecha y ornamentos (cuentas, espiraliformes, brazaletes) y de forma mayoritaria en hachas planas y punzones (Soriano 2013: 155, anexo 3). Los resultados composicionales de los crisoles y restos de colada de Minferri y Can Roqueta II muestran también el empleo de bronce (Rovira et al. 1997: 254; Rovira Hortalà 1998: 244). De esta manera podemos apuntar, en base al contexto regional y a título de hipótesis, el uso del crisol en la obtención de bronce, aunque sin poder descartar totalmente la fundición de cobre puro.

\section{CRISOLES CON SISTEMA DE PRENSIÓN EN LA PENÍNSULA IBÉRICA}

Los crisoles son herramientas escasas en el área de estudio. Hay un ejemplar de cronología

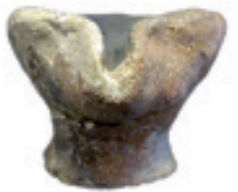

1

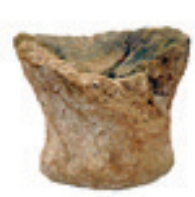

4
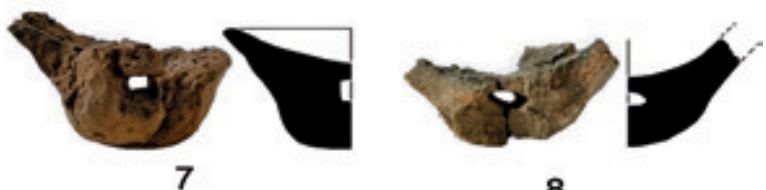

8
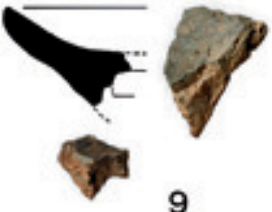

9

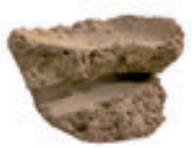

2

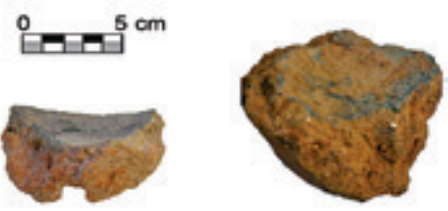

6
Fig. 4. Crisoles con sistema de prensión en la Península Ibérica: 1. Can Mur (fotografía Nicolau Escanilla); 2 y 3. Cantorella (Maldà, Lleida) (Escala et al. 2014: 150 Fig. 16); 4 a 6. Can Roqueta II (Sabadell, Barcelona), estructuras CRII-654 UE-1, CRII-634 UE-6 y CRII-44 UE-1 respectivamente (fotografías Ignacio Soriano); 7 a 9. Minferri (Juneda, Lleida), estructuras SJ-286 UE-8397 (ejemplares 7 y 8) y FI-159 UE-7126 (ejemplar 9) (López y Moya 2009); 10 y 11. Peña la Dueña (Teresa, Castellón) (Simón 1998: 183, Fig. 105.1-3).

\begin{tabular}{|c|c|c|c|c|c|c|c|c|c|c|c|c|c|c|}
\hline $\begin{array}{c}\mathrm{N}^{\circ} \\
\text { ANAL. }\end{array}$ & OBJETO & ZONA & FE & NI & CU & ZN & AS & AG & SN & SB & AU & PB & BI & Otros \\
\hline $\begin{array}{c}\text { PA } \\
20783 \mathrm{~A}\end{array}$ & $\begin{array}{c}\text { Crisol } \\
\text { con pie }\end{array}$ & $\begin{array}{c}\text { Borde } \\
\text { zona } 1\end{array}$ & 5,22 & nd & 0,06 & nd & nd & nd & nd & nd & nd & nd & nd & LE=94,1 \\
\hline $\begin{array}{c}\text { PA } \\
\text { 20783B }\end{array}$ & $\begin{array}{c}\text { Crisol } \\
\text { con pie }\end{array}$ & $\begin{array}{c}\text { Borde } \\
\text { zona 2 }\end{array}$ & 5,04 & nd & 0,09 & nd & nd & nd & nd & nd & nd & nd & nd & LE=94,2 \\
\hline $\begin{array}{c}\text { PA } \\
\text { 20783C }\end{array}$ & $\begin{array}{c}\text { Crisol } \\
\text { con pie }\end{array}$ & Base pie & 5,68 & nd & 0,03 & 0,02 & nd & nd & nd & nd & nd & nd & nd & LE=93,4 \\
\hline $\begin{array}{c}\text { PA } \\
\text { 20783D }\end{array}$ & $\begin{array}{c}\text { Crisol } \\
\text { con pie }\end{array}$ & $\begin{array}{c}\text { Pico } \\
\text { vertedero }\end{array}$ & 6,02 & nd & 0,08 & nd & nd & nd & nd & nd & nd & 0,01 & nd & LE $=93,3$ \\
\hline
\end{tabular}

Tab. 1. Resultados del análisis de composición (FRXp) efectuado en diferentes puntos del crisol de Can Mur. No Anal.: Número de análisis; nd: no detectado; LE: light elements. Valores expresados en \% en peso. 


\begin{tabular}{|c|c|c|c|c|c|c|c|c|}
\hline YACIMIENTO & $\begin{array}{l}\text { OBJ. MET. } \\
\text { ASOCIADO }\end{array}$ & $\begin{array}{l}\text { CÓDIGO } \\
\text { LAB }\end{array}$ & VALOR BP & $\begin{array}{l}\text { RANGO } \\
\text { CAL BC } 1 \\
\text { SIGMA }\end{array}$ & $\begin{array}{l}\text { VALOR } \\
\text { CAL BC } 1 \\
\text { SIGMA }\end{array}$ & MUESTRA & CONTEXTO & BIBLIOGRAFÍA \\
\hline Minferri & Crisol & UBAR-551 & $\begin{array}{c}3660 \pm 280 \\
(*)\end{array}$ & $2457-1696$ & 2089 & Carbón & $\begin{array}{c}\text { Silo SJ-55, } \\
\text { UE-7010 }\end{array}$ & $\begin{array}{c}\text { Equip Minferri } \\
\text { 1997; Rovira } \\
\text { Hortalà } 1998\end{array}$ \\
\hline Minferri & $\begin{array}{l}\text { Restos de } \\
\text { colada de } \\
\text { bronce }\end{array}$ & UBAR-548 & $3590 \pm 110$ & $2129-1772$ & 1941 & Carbón & $\begin{array}{c}\text { Silo SJ-33, } \\
\text { UE-5034 }\end{array}$ & GIP 2002 \\
\hline Minferri & Molde hacha & UBAR-549 & $3510 \pm 60$ & $1905-1751$ & 1827 & Carbón & $\begin{array}{l}\text { Silo SJ-53, } \\
\text { UE-707 }\end{array}$ & GIP 2002 \\
\hline Camp Cinzano & Molde puñal & UBAR-1007 & $3505 \pm 40$ & $1886-1771$ & 1827 & $\begin{array}{l}\text { Hueso } \\
\text { humano }\end{array}$ & $\begin{array}{c}\text { Fosa/silo } \\
\text { funerario } \\
\text { individual } \\
\text { E-18, estrato } \\
1801\end{array}$ & $\begin{array}{c}\text { Soriano y Amorós } \\
2014 \mathrm{a}\end{array}$ \\
\hline Minferri & 2 Crisoles & Beta- 92280 & $3410 \pm 90$ & $1877-1615$ & 1730 & Fauna & $\begin{array}{l}\text { Fosa/silo } \\
\text { funerario SJ- } \\
\text { 88, UE-2121 } \\
\text { (2 ind.) }\end{array}$ & $\begin{array}{l}\text { Equip Minferri } \\
1997\end{array}$ \\
\hline Can Roqueta & $\begin{array}{c}\text { Molde para } \\
\text { hacha y varilla }\end{array}$ & UBAR-800 & $3360 \pm 70$ & $1741-1535$ & 1645 & Fauna & $\begin{array}{l}\text { Cámara con } \\
\text { pozo de } \\
\text { acceso CRII- } \\
\text { 36, capa } 4 \text { (2 } \\
\text { ind.) }\end{array}$ & Carlús et al. 2008 \\
\hline Forat de la Tuta & $\begin{array}{c}3 \text { Moldes para } \\
\text { hacha, varillas } \\
\text { y hacha } \\
\text { + varillas. } \\
\text { Mineral cobre }\end{array}$ & LTL-4236A & $3335 \pm 45$ & $1683-1535$ & 1619 & $\begin{array}{c}\text { Hueso } \\
\text { humano }\end{array}$ & $\begin{array}{c}\text { Tumba de } \\
\text { metalúrgico }\end{array}$ & Soriano 2011 \\
\hline
\end{tabular}

Tab. 2. Dataciones absolutas relacionadas con la producción metalúrgica en el nordeste de la Península Ibérica (programa empleado Calib Rev. 7.1, Reimer et al. 2013). El valor calibrado es el resultado de la media de la datación calibrada a $1 \sigma$ ponderada por cada uno de los rangos de valores probables existentes (Soriano 2013: 5). Minferri (Juneda, Lleida); Camp Cinzano (Vilafranca del Penedès, Barcelona); Can Roqueta II (Sabadell, Barcelona); Forat de la Tuta (Riner, Lleida). Obj. met.=objetos metalúrgicos; Lab.=Laboratorio; $(*)=$ Datación con desviación típica demasiado amplia que aconseja excluirla.

campaniforme en Bauma del Serrat del Pont (Alcalde et al. 1998: 91). Los demás pertenecen al Bronce Inicial y se concentran en tres únicos asentamientos del tipo "agrupación de fosas" donde aparecen de forma sincrónica crisoles con y sin sistema de prehensión. Hay un cuarto yacimiento peninsular con crisoles similares ubicado en la parte norte de la fachada levantina. En todos ellos hay evidencias metalúrgicas de fundición y acabado de objetos metálicos pero no de reducción de mineral (Figs. 1 y 4, Tab. 2).

\subsection{Can Roqueta II (Sabadell, Barcelona)}

Localizado en la Depresión Prelitoral catalana, el paraje de Can Roqueta muestra un uso conti- nuado desde el Neolítico Antiguo hasta la actualidad. La ocupación del Bronce Inicial comprende casi 200 estructuras de tipo habitacional (fosas/silos, fondos de cabaña, estructuras de combustión) y funerario (fosas, cámaras con pozo de acceso). Está fechada por 15 dataciones C14 (c. 2300-1200 cal BC cal BC) (Palomo y Rodríguez 2004; Carlús et al. 2007; Carlús et al. 2008).

Las evidencias de producción metalúrgica se concentran en el sector de Can Roqueta II. Son fragmentos de un crisol hemisférico con paredes lisas y adherencias metálicas en su interior. Se desconoce el número de restos de fundición y de moldes metalúrgicos recuperados, todos de tipo monovalvo cerrado. Se constata con seguridad un ejemplar para hacha y objeto indeterminado (¿varilla/lingote?) y dos más para varillas. Restan 
otros dos para varillas pendientes de corroborar por su estado fragmentario y la posibilidad de que fueran afiladores o pulidores. Los objetos metálicos son dos aros/anillas y un punzón ${ }^{5}$ (Rovira Hortalà 2006: 139-143; Rovira et al. 2007; Soriano 2013: 66-67, 74-77, 130). Los análisis de residuos de fundición y de objetos metálicos muestran que siempre se empleó bronce; y los metalográficos la aplicación de procesos de forja en frío y recocido, y de forja en frío + recocido + forja en frío (Rovira Hortalà 2006: 141, Fig. 5). La única datación $\mathrm{C} 14$ vinculada con la metalurgia, en concreto con el molde para hacha y objeto indeterminado, está situada c. 1650 cal BC (Tab. 2).

A estos datos hay que sumar un crisol con pie macizo y fuertes afinidades con el ejemplar de Can Mur, y dos con perforación para el enmangue (Fig. 4.4-6) (Rovira Hortalà 2006: 140; Rovira et al. 2007). Los tres tienen adherencias metálicas y son de tendencia hemisférica. $\mathrm{Su}$ estado fragmentario no permite afirmar si dispondrían de pico vertedero. El primero está compuesto por un pequeño receptáculo ovoide de paredes lisas, sostenido por un pie macizo de base plana umbilicada. Procede del estrato $1 \mathrm{de}$ la fosa/silo CRII-654, rellena con tres estratos de material de desecho. El segundo conserva en la base parte de la perforación para el enmangue, de sección cuadrangular. Se halló en el estrato 6 de la fosa/silo funeraria CRII-644, el estrato más antiguo situado en la base de la estructura, sin vinculación alguna con el uso funerario de la misma. En el tercero no hay rastro de ella, razón por la que fue publicado como carente de sistema de prehensión (Rovira et al. 2007: 507). Sin embargo el ancho espesor de la pieza en su parte inferior apunta, en nuestra opinión, a un crisol de este tipo. Su contexto de aparición fue la fosa/silo con material de desecho CRII-44, rellena con un único estrato ${ }^{6}$.

\footnotetext{
5 Rovira Hortalà, Ma . C. 2003: “Can Roqueta II (SabadellVallès Occidental). Els materials de caire metàl-lic i metallúrgic". En A. Rodríguez y A. Palomo 2003. Memòria dels treballs arqueològics desenvolupats a Can Roqueta II (SabadellVallès Occidental) 1999/2000. Inédita, Servei d'Arqueologia i Paleontologia, Generalitat de Catalunya. Sabadell: anexo $\mathrm{n}^{\mathrm{o}} 7$.

${ }^{6}$ Rodríguez, A. y Palomo, A. 2003: Memòria dels treballs arqueològics desenvolupats a Can Roqueta II (Sabadell-Vallès Occidental) 1999/2000. Text, fitxes d'estructures $i$ inventaris (3 vols.). Inédita, Servei d'Arqueologia i Paleontologia, Generalitat de Catalunya. Sabadell.
}

\subsection{Minferri (Juneda, Lleida) ${ }^{7}$}

Localizado en el llano de Lleida, se han documentado cerca de 450 estructuras de tipo similar a las ya citadas para Can Roqueta. El yacimiento cuenta con una ocupación durante el Calcolítico Antiguo (3 dataciones, c. 3450-3100 cal BC) y otra, de mayor envergadura, que se extiende a lo largo del Bronce Inicial dentro del lapso temporal c. 2100 - 1200 cal BC (13 dataciones) (Equip Minferri 1997; GIP 2002; Nieto Espinet et al. 2014).

Los datos sobre la producción metalúrgica son los más completos de toda el área de estudio y se reparten por más de 40 estructuras. Se documentan (Rovira Hortalà 1998; Soriano 2013: 64-70, $77,106)^{8}$ : una cubeta metalúrgica; 10 moldes del tipo monovalvo cerrado, para hachas, cinceles/ escoplo y varillas; abundantes restos de fundición; un posible martillo o yunque de forja; y un mínimo de 27 crisoles hemisféricos, además de fragmentos de tres o cuatro crisoles con perforación para el enmangue. Los objetos metálicos se limitan a un fragmento distal de puñal de remaches y a dos punzones. Los análisis efectuados hasta el momento, tanto en adherencias metálicas en crisoles como en restos de fundición y objetos de metal, revelan que se fundió bronce en todos los casos (Rovira et al. 1997: 254).

Los crisoles con perforación para el enmangue comparten características similares (Fig. 4.7-9) ${ }^{9}$ : morfología hemisférica, amplio engrosamiento en la base con una perforación que atraviesa el vaso y se va estrechando ligeramente, y ausencia de decoración. Todos son materiales de desecho procedentes del interior de fosas/silos. Los dos crisoles mejor conservados tienen perforación de sección cuadrangular y ovalada respectivamente. Provienen del mismo contexto (SJ-286 UE-8397) y tienen gotas metálicas sobre su superficie. El primero conserva restos de un pico vertedero. Desconocemos si los demás lo tendrían también.

\footnotetext{
${ }^{7}$ Este yacimiento está en proceso de estudio de manera que los datos expuestos deben considerarse preliminares.

${ }^{8}$ López, J. B. y Moya, A.: "Gestión y metalurgia del bronce en la aldea de Minferri (Juneda, Lleida) 2100-1650 cal. ANE". Poster presentado en Archaeometallurgy: Technological, economic and social perspectives in Late Prehistoric Europe (TESME). Meeting in honour of Salvador Rovira (Madrid, 2009). Instituto de Historia, CSIC. Madrid.

${ }^{9}$ Véase n. 8.
} 
El tercer ejemplar se recuperó en el estrato UE7126 de la estructura FI-159 y muestra restos de la perforación en la base, que sería de sección cuadrangular. El último caso (SJ-299 UE-8413) podría, quizás, incluirse en este tipo de crisoles. Como ocurría en un ejemplar de Can Roqueta II, el engrosamiento de su parte inferior parece remitir al sistema de prensión, actualmente no conservado. La alta fragmentación de estas piezas y el hecho de que ese sistema solo pueda identificarse si se localiza la parte perforada abre la posibilidad a que algunos de los clasificados como hemisféricos dispusieran, en realidad, de sistema de prensión. Sugiere la sincronía de ambos grupos de crisoles el hecho que, a veces, compartan estructura (SJ-286 UE-8395 y 8397) e incluso estrato (FI-159 UE-7126). Es posible que su uso fuera complementario, quizás vinculado a diferentes actividades metalúrgicas o a la obtención de objetos de diverso tamaño, tal y como apuntan las grandes diferencias existentes en su capacidad (Rovira Hortalà 2006; Soriano 2013: 66, 156, Fig. 9).

Las dataciones $\mathrm{C} 14$ asociadas con la producción metalúrgica se sitúan c. 2100-1700 cal BC, aunque ninguna de ellas se vincula con crisoles con perforación (Tab. 2) ${ }^{10}$.

\subsection{Cantorella (Maldà, Lleida)}

Localizado en la Vall del Corb, en el llano de Lleida, presenta estructuras idénticas a los anteriores. Se carece de dataciones C14 pero los materiales permiten establecer una ocupación en el Calcolítico sensu lato y otra en el Bronce Inicial, con 69 y 47 estructuras adscritas respectivamente. Más de un centenar de estructuras prehistóricas quedan pendientes de asignación (Escala et al. 2014).

Los únicos elementos vinculados con la metalurgia son dos crisoles de morfología hemisférica y un engrosamiento en la base, donde se ubica la perforación de sección cuadrangular (Fig. 4.2-3). La ausencia de los bordes impide saber si presentarían pico vertedero y/o algún tipo de decoración. La perforación del primero se va estrechando has-

\footnotetext{
${ }^{10}$ Véase n. 8.
}

ta atravesar completamente la pieza. El segundo presenta un engrosamiento macizo de perfil cilíndrico y base plana, con ciertas similitudes con los ejemplares de pie macizo de Can Mur y Can Roqueta II pero perforado. En este caso el orificio no llega a atravesar la pieza (Escala et al. 2014: 148-150). Los crisoles proceden de dos fosas/silos diferentes y carecen de análisis arqueometalúrgicos.

\subsection{Peña la Dueña (Teresa, Castellón)}

Asentamiento en altura en el Valle del Palancia. Presenta una muralla de piedra seca que defiende el acceso y varios muretes que delimitan espacios habitacionales. En una de estas habitaciones se documentaron tres sepulturas individuales acompañadas de pequeñas vasijas lisas y, en un caso, un molino de mano. La presencia de crisoles con sistema de prensión, debido a su "complejidad tecnológica” (Simón 1998: 181), ha justificado la ubicación del yacimiento a finales del Bronce Pleno o inicios del Bronce Tardío. Consideramos esta atribución, aceptada por uno de nosotros recientemente (Soriano y Amorós 2014b: 380), carente de justificación. Los materiales, aún desprovistos de contexto estratigráfico, remiten al Bronce Antiguo - Medio: grandes contenedores con cordones incisos, vasos carenados, cerámica de cocción reductora con superficie espatulada, etc. (Alcocer Grau 1945: 151-158; Palomar Macian 1995: 146-148).

Como elementos metalúrgicos se recuperaron escoria metálica (no analizada), un fragmento de crisol de borde recto y morfología indeterminada y dos crisoles con perforación para el enmangue. Sus características son idénticas (Fig. 4.9 y 10): morfología hemisférica, paredes gruesas, bordes rectos decorados con impresiones digitales, pico vertedero y ligero engrosamiento en la base con una perforación de sección ovalada que alcanza la mitad del vaso, sin llegar a atravesarlo. Del interior de los tres crisoles se obtuvieron adherencias metálicas, igualmente sin analizar (Simón 1998: 181).

A modo de resumen, para el nordeste contamos con un total de dos crisoles con pie macizo, procedentes de Can Mur y Can Roqueta II, y siete/ ocho crisoles con perforación para el mango loca-

Trab. Prehist., 73, N. ${ }^{\circ}$ 1, enero-junio 2016, pp. 160-179, ISSN: 0082-5638

doi: $10.3989 /$ tp.2016.12169 
lizados en Can Roqueta II, Minferri y Cantorella. Del resto de la Península Ibérica únicamente conocemos los dos crisoles con perforación de Peña la Dueña. A pesar de ello, y como se ha visto en Minferri, no podemos obviar la posibilidad de que otros crisoles fragmentados, cuya morfología nos es desconocida, tuvieran originariamente algún sistema de prensión similar a los expuestos.

En el nordeste la cronología de estos crisoles, aun disponiendo de pocas dataciones $\mathrm{C} 14$, puede situarse de forma orientativa en la primera mitad del II milenio cal BC (c. 2100-1650 cal BC) (Tab. 2). Todas las piezas provienen de contextos de desecho en asentamientos en "agrupación de fosas". A falta de mayor número de análisis, los datos actuales sugieren que el metal fundido es bronce. En el Levante nos es imposible situar con precisión el momento de aparición de estos útiles pero la información disponible apunta hipotéticamente a su adscripción al Bronce Antiguo - Medio. El único contexto que conocemos corresponde a una estructura habitacional en piedra en un asentamiento en altura (Peña la Dueña) y carecemos de datos analíticos de las adherencias metálicas de los crisoles.

\section{TRAZANDO EL ORIGEN. CRISOLES CON SISTEMA DE PREHENSIÓN EN PRÓXIMO ORIENTE Y EUROPA}

Los crisoles con sistema de prensión están documentados desde el IV milenio cal BC en numerosos yacimientos de Próximo Oriente y Europa. No es nuestro objetivo realizar un catálogo exhaustivo de todos ellos sino únicamente reseñar los que muestran semejanzas tipológicas con los casos de la Península Ibérica. Por ello, nos centraremos en los que tienen una perforación para el enmangue $y / o$ un engrosamiento en la base (Figs. 1, 5 y 6).

Las primeras evidencias de las que tenemos constancia provienen de Irán (Fig. 5.1-2 y 6.1) (Thornton 2014: 677-680). Un crisol con pie macizo fue recuperado en el yacimiento de Cheshmeh Ali (Teherán). La pieza, que presenta adherencias metálicas en su interior, se fecha c. 4300-4000 cal BC. De Tepe Ghabristan (Gazvin) proceden dos crisoles de cuerpo hemisférico con pico vertedero $\mathrm{y}$ engrosamiento en forma de pedestal, pero ade-
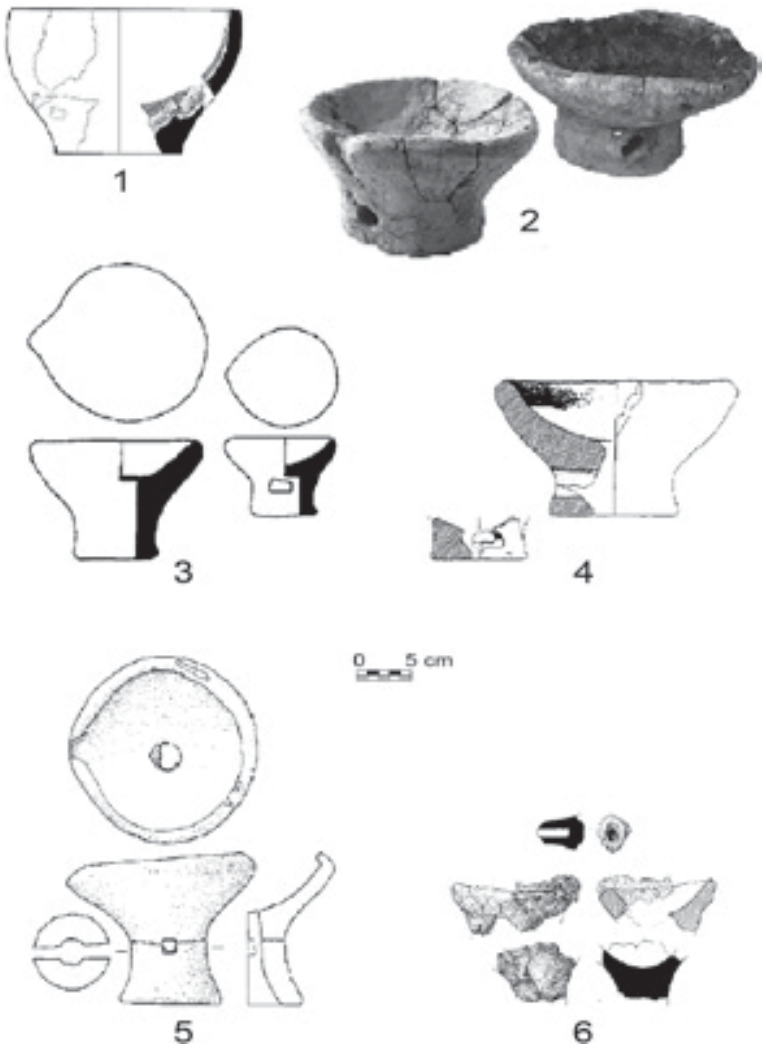

4

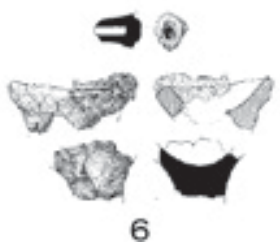

Fig. 5. Crisoles con engrosamiento en la base donde se localiza la perforación para el enmangue: 1. y 2. Cheshmeh Ali (Teherán) y Tepe Ghabristan (Gazvin), en Irán (Thornton 2014: 677 y 678, Fig. 23.3 y 23.4); 3. Tumbas 10 y 45 de Aghia Photia, (Siteia, Creta, Grecia) (Betancourt y Muhly 2007: 147, Fig. 9.1); 4. y 5. Castellaro del Vhò (Piadena, Lombardía) y Montale (Castelnuovo Rangone, Emilia Romaña), en Italia (Cierny et al. 2002: 50, Fig. 8.9-15; Marzatico 1997: 585 Fig. 377.90); 6. Lède du Gurp (Grayan-et-l'Hòspital, Aquitania, Francia) (Roussot- Larroque 1997: 40, Fig. 2).

más con perforación para insertar el mango. El conducto es oval y desconocemos si atraviesa o no toda la base del crisol. Estas piezas están fechadas c. 4000-3700 cal BC (periodo Ghabristan II). Crisoles idénticos se localizan en asentamientos como Arisman y Tepe Sialk (Kashan) en una cronología algo posterior (c. 3700-3400 cal BC, periodo Sialk $\left.\mathrm{III}_{6-7}\right)$. Contemporáneamente a la evidencia de Tepe Ghabristan se documentan otro tipo de crisoles en Qaleh Gusheh (Natanz). También son de tipo hemisférico pero la perforación para el mango se sitúa en un apéndice lateral en vez de en la base del crisol como los anteriores. 


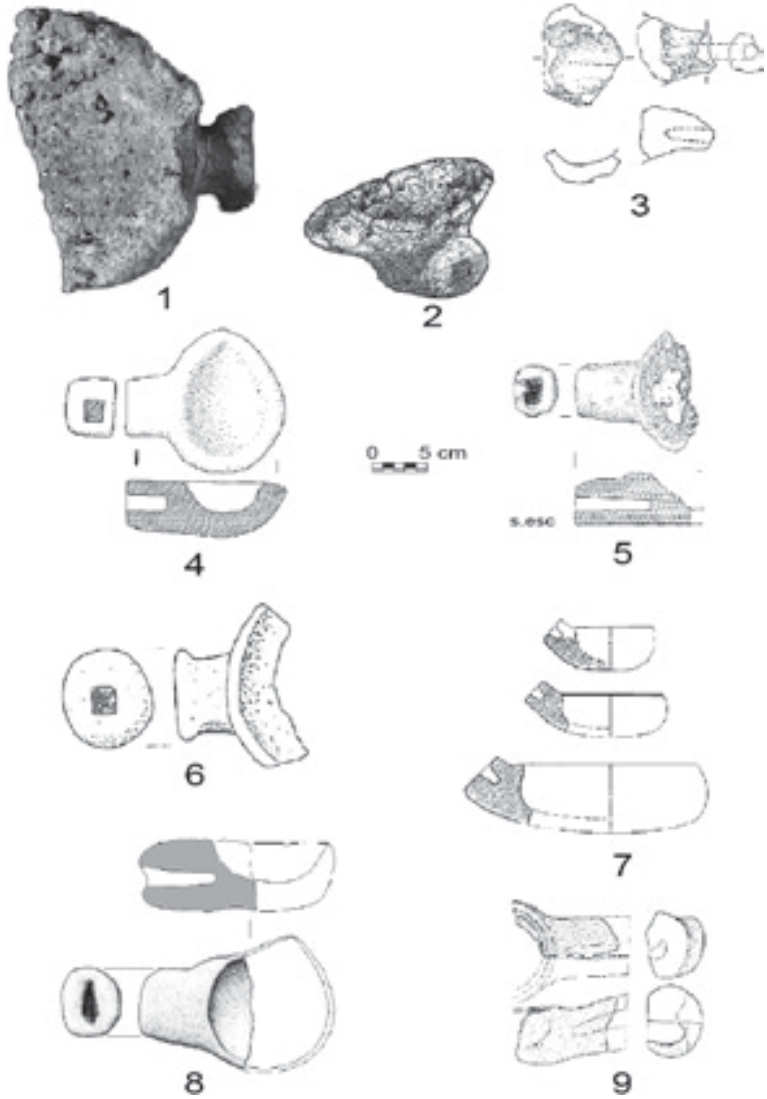

Fig. 6. Crisoles con apéndice lateral perforado: 1. Qaleh Gusheh (Natanz, Irán) (Thornton 2014: 680, Fig. 23.5); 2. Lerne IV (Argólida, Grecia) (Tylecote 1976: 18, Fig. 10); 3. Mozartstrasse (Zurich, Suiza) (Fasnacht 1991: 163, Fig. 2.1); 4. y 5. Lago di Ledro y Fiavé (Trento, Italia) (Rageth 1974: Fig. 89-90; Perini 1987: 34, fig 14.1); 6. Monte d'Accodi (Sassari, Cerdeña) (Camps 1990-1991: 44, Fig. 7.1); 7. y 8. Terrina IV (Aléria) y Alo-Bisughjè (Bilia), ambos en Córcega (Camps 1990-1991: 44, Fig. 6; Peche-Quilichini 2014: 130, Fig. 1.7); 9. Beaussement (Ardèche, Rhône-Alpes, Francia) (Carozza y Ambert 1996: 49, Fig. 40.3).

Dicha perforación es cuadrangular y, lógicamente, no atraviesa la cerámica en su totalidad.

Se constatan, pues, tres conjuntos de crisoles diferenciados: con pie macizo, con engrosamiento en la base donde se localiza la perforación para el enmangue y con apéndice lateral con perforación para insertar el mango. El grupo con pie macizo es el más antiguo mientras que los dos restantes son un poco más tardíos y sincrónicos. Son estos dos últimos grupos los que se constatan con posterioridad en diferentes yacimientos europeos $\mathrm{y}$, de forma similar a los iraníes, conviven a lo largo de varios milenios.

En el contexto europeo, el segundo grupo es el más coincidente con los documentados en el área de estudio. Presenta cuerpo hemisférico, pico vertedero y un engrosamiento en la base en el que se localiza la perforación para insertar el mango. Tanto la morfología de dicho engrosamiento como la sección de la perforación (cuadrangular u oval) varía, sin que se haya podido observar un patrón específico. La presencia o no de pico vertedero es difícil de constatar debido a la fragmentación de las piezas (Figs. 1 y 5). Los más antiguos provienen del Mediterráneo Oriental. Dos ejemplares de las tumbas 10 y 45 de la necrópolis minoica de Aghia Photia (Siteia, Creta) presentan pico vertedero y un orificio de sección cuadrangular que los atraviesa por completo (Fig. 5.3) (Betancourt y Muhly 2007). El análisis de las adherencias metálicas indica la fundición de cobre. Los contextos de hallazgo se sitúan en el periodo Prepalacial, entre finales del Minoico Antiguo I e inicios del Minoico Antiguo IIA (c. 3200-2600 cal BC). En este yacimiento abundantes evidencias denotan conexiones e influencias con las islas Cícladas, área donde aparece el segundo conjunto de crisoles (véase infra). Durante toda la Edad del Bronce en la isla de Creta se siguen empleando crisoles idénticos en asentamientos como Cnossos, Malia, Pyrgos-Myrtos y Kommos (Blitzer 1995: 502505; Oberweiler 2011: 433-436).

En un momento posterior se conocen ejemplares similares en el norte de Italia. No tenemos constancia de su presencia entre los grupos de Polada (c. 2200-1600 cal BC) pero sí en las Terramaras (c. 1600-1325 cal BC). En Castellaro del Vhò (Piadena, Cremona, Lombardía) se han recuperado fragmentos de siete ejemplares aunque no es posible asegurar que todos correspondan a este tipo concreto (Fig. 5.4). Los mejor conservados tienen base plana y perforación de sección oval mientras que en otros el pico vertedero es visible. El contexto está datado en el Bronce Medio 2, c. 1550-1450 cal BC (Cierny et al. 2002). Menos claro es el ejemplar de la terramara de Montale (Castelnuovo Rangone, Módena, Emilia Romaña) (Fig. 5.5). Su morfología es de tipo copa, con pico vertedero y perforación de sección cuadrangular que atraviesa todo el útil. Muestra un orificio circular vertical de función desconocida. Lo traspasa hasta la base y comunica con el canal para in-

Trab. Prehist., 73, N. ${ }^{\circ}$ 1, enero-junio 2016, pp. 160-179, ISSN: 0082-5638

doi: $10.3989 /$ tp.2016.12169 
sertar el mango. La pieza carece de contexto y, según las dataciones $\mathrm{C} 14$, el yacimiento se ocupa durante todo el lapso temporal de las Terramaras (Marzatico 1997: 585-586).

En la costa atlántica francesa, en el asentamiento metalúrgico de Lède du Gurp (Grayanet-l'Hòspital, Gironde, Aquitania) se localizan cuatro ejemplares más (Fig. 5.6). Dos muestran engrosamiento en la base (de morfología indeterminada) y otro un apéndice con perforación para el enmangue de sección oval, sin atravesar completamente la pieza. El fragmento perteneciente al cuarto ejemplar no permite identificar su morfología. Estos datos indican que, o bien son crisoles de diferentes tipos (con engrosamiento en la base -perforado o no- y con apéndice lateral perforado) o bien se trata de un tipo mixto, con base engrosada y perforación localizada en un apéndice lateral. Dos de los crisoles presentan adherencia metálicas. El análisis de una de ellas indica bronce. Dos dataciones C14 ubican el yacimiento en el Bronce Medio (c. 1700-1600 cal BC) (Roussot-Larroque 1997: 40-43, 2007: 289).

El tercer grupo de crisoles, con apéndice lateral perforado, es el más numeroso y su morfología se diferencia con claridad de la de los anteriores. Además del apéndice presentan cuerpo hemisférico y pico vertedero. Este conducto puede, de nuevo, ser tanto de sección oval como cuadrangular y la presencia o no de pico vertedero es difícil de afirmar en piezas fragmentadas (Figs. 1 y 6). En el Mediterráneo Oriental se constatan en islas del Egeo como Thermi (Lesbos), Héraion (Samos) o en el archipiélago de las Cícladas: Kastri (Syros), Kephala (Ceos) y Phylkopi (Melos) (Oberweiler 2011: 439). En la Grecia continental aparecen en Lerne IV (Argólida) y Sesklo (Tesalia) (Fig. 6.2) (Tylecote 1976: 18; Pearce 2013: 44). En todos estos yacimientos hay un único ejemplar con perforación de sección cuadrangular excepto en Sesklo, que es oval. Los crisoles de las islas del Ego se emplean durante el Minoico Antiguo y el de Lerne en torno al Heládico Medio (c. 21001550 cal BC), desconociéndose la cronología del procedente de Sesklo.

En Suiza un ejemplar con perforación de sección oval del estrato 3 de Mozartstrasse (Zurich) se asocia con el grupo Horgen (c. 3200-2900 cal BC) (Fasnacht 1991) (Fig. 6.3). Los crisoles de Lago di Ledro y Fiavé (Trento, Tentino-Alto Adigio), en el norte de Italia, vinculados a los grupos de Polada (Fig. 6.4-5) no están demasiado alejados. En el primer yacimiento se recuperaron fuera de contexto ocho crisoles con orificio de sección cuadrangular y pico vertedero en los estratos IV a I, fechados en el Bronce Antiguo-Medio pero con evidencias también del Calcolítico (Battaglia 1943). De la capa IV del segundo yacimiento procede un ejemplar, con perforación de sección cuadrangular, fechado de forma relativa a inicios del Bronce Medio (Perini 1987: 34).

De Cerdeña provienen dos crisoles con perforación de sección oval y restos de cobre de Monte d'Accodi (Sassari) fechados en la fase Filigosa (c. 2850-2600 cal BC) (Lo Schiavo 2005: 263, 270-273) (Fig. 6.6). En Córcega, en Terrina IV (Aléria), contamos con fragmentos de veinticinco crisoles más, con orificio de sección cuadrangular (Fig. 6.7). Proceden de una fosa/silo con materiales de desecho. Destacan una tobera, restos de colada y un punzón metálico. Los análisis de los crisoles y del resto de elementos metálicos mostraron, en todos los casos, una composición de cobre puro (Camps 1988: 239-253, 1990-1991). Una reciente revisión de las dataciones $\mathrm{C} 14$ de este yacimiento sitúa el contexto, de forma aproximada, entre c. 3250-2400 cal BC (Pearce 2013: 54). En la misma isla, en el asentamiento turriforme de Alo-Bisughjè (Bilia), se halló un ejemplar con perforación oval (Fig. 6.8). Según las fechas C14 se ocupó desde finales del Bronce Antiguo hasta el Bronce Final (c. 2200-1300 cal BC) (PecheQuilichini 2007: 13-14). Este crisol y otros tres de morfología hemisférica y sin sistema de prensión carecen de contexto. Sobre la base del estudio cronotipológico del material cerámico todos ellos se han situado entre finales del Bronce Antiguo y mediados del Bronce Medio (Peche-Quilichini 2014: 130-131) ${ }^{11}$.

El último crisol del que tenemos noticia procede del asentamiento francés de Beaussement (Ardèche, Rhône-Alpes) (Fig. 6.9). La pieza, con perforación de sección oval, presenta adherencias metálicas y se fecha c. 2600-2400 cal BC (Carozza y Ambert 1996: 48-49).

\footnotetext{
11 Durante la redacción de este artículo hemos sabido por un documental de carácter divulgativo que se ha localizado otro crisol corso en Monticello (c. 3200-2500 cal BC). Desconocemos el contexto concreto del útil y su cronología precisa (http:// www.inrap.fr/archeologie-preventive/Ressources/p-19447-Monticello-un-etablissement-metallurgique-neolithique.htm) (consulta 20 -VI-2015)
} 
En resumen, ambos grupos de crisoles son contemporáneos incluso desde el momento de su surgimiento (desde el IV al II milenio cal ANE). Además su sincronía es espacial, como atestiguan el Egeo y el norte de Italia. El primer metal fundido fue el cobre (ejemplares del Calcolítico de Aghia Photia, Monte d'Accodi, Terrina IV) mientras que en la Edad del Bronce se documenta bronce (Castellaro del Vhò, Lède du Gurp, Minferri o Can Roqueta II).

Estos crisoles pudieron estar en uso a la vez que otros sin sistema de prensión, tal y como apunta el yacimiento corso de Alo-Bisughjè o el de Minferri en la Península Ibérica. Aquí su distribución se concentró en el nordeste sin que haya evidencias más hacia el interior. Por ello debemos rastrear su origen siguiendo la costa del Sur de Francia o las islas occidentales del Mediterráneo

Finalmente, los crisoles con pie macizo y sin perforación solo se documentan en el $\mathrm{V}$ milenio cal BC en Irán. Su constatación en el nordeste puede interpretarse como una solución local a los crisoles con engrosamiento en la base y perforación para enmangue que se extienden por Europa y el Mediterráneo durante dos milenios. Tampoco debemos olvidar que el crisol de Cantorella con pie de base plana y una perforación constituye otro caso atípico o intermedio.

\section{ORGANIZACIÓN E INNOVACIÓN TECNOLÓGICA. LA METALURGIA DEL BRONCE INICIAL EN EL NORDESTE}

\subsection{Estructuración e interdependencia}

La organización de la producción metalúrgica durante el Bronce Inicial muestra diferencias relevantes respecto a la del Calcolítico. Durante el Bronce Inicial se observa por primera vez una segmentación e interdependencia geográfica del proceso metalúrgico. La extracción del mineral, su reducción y la fundición del metal se llevan a cabo en diferentes asentamientos o enclaves. $\mathrm{Su}$ interrelación es altamente plausible, ya que en cada uno se documenta una única fase del proceso metalúrgico. Estas relaciones se extienden al ámbito de la distribución, al constatarse

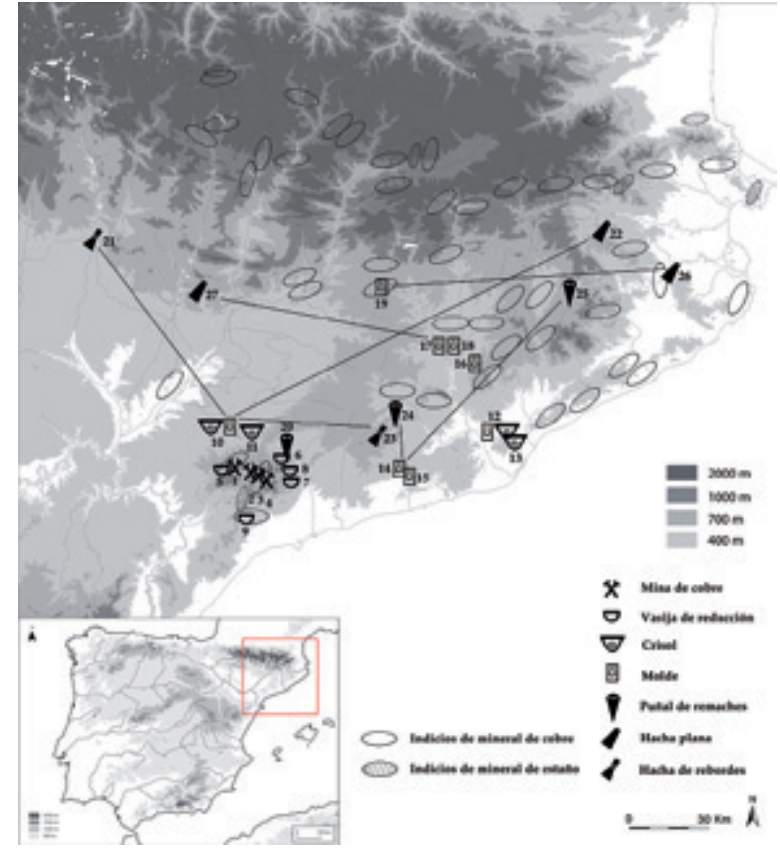

Fig. 7. Localización de yacimientos metalúrgicos en el nordeste de la Península Ibérica durante el Bronce Inicial, en relación a las principales mineralizaciones de cobre y estaño (a partir de Martín et al. 1999: 123 y del Modelo Digital del Terreno del Instituto Geográfico Nacional serie MDT200). Los vinculados con actividades de extracción y reducción se concentran en la provincia de Tarragona (1-9). Las líneas indican coincidencia morfométrica entre moldes y artefactos metálicos. Extracción: 1. Solana del Bepo (Ulldemolins); 2. y 3. Barranc Fondo y Mina de la Turquesa (Cornudella de Montsant); 4. Els Crossos (Alforja). Reducción: 5. Coveta de 1'Heura (Ulldemolins); 6. Balma del Duc (Montblanc); 7. Cova del Cartanyà (Vilaverd); 8. Cova del Buldó (Rojals); 9. Cova Josefina (Escornalbou). Fundición y acabado: 10. Minferri (Juneda, Lleida); 11. Cantorella (Maldà, Lleida); 12. Can Roqueta II (Sabadell, Barcelona); 13. Can Mur (Valldoreix, Barcelona); 14. y 15. Camp Cinzano y el Bordellet (Vilafranca del Penedès, Barcelona); 16. Mura (Barcelona); 17. Comarca del Bages (Barcelona). 18. Comarca del Bages (Barcelona) o Solsonès (Lleida); 19. Forat de la Tuta (Riner, Lleida). Objetos metálicos: 20. Cova Font Major (Espluga del Francolí, Tarragona); 21. Paules (Barbastro, Huesca); 22. Croscat (Sta. Pau, Girona); 23. Plana d'Ancosa (Querol, Tarragona); 24. Cova de Mas Vilà (Sta. Maria de Miralles, Barcelona); 25. Cova de les Grioteres (Vilanova de Sau, Barcelona); 26. Posiblemente Girona (Museu d'Arqueologia de Catalunya - Girona, $\mathrm{n}^{\circ}$ 201.820); 27. Cova de Joan d'Os (Les Avellanes i Sta. Linya, Lleida).

el movimiento de productos finales entre asentamientos distantes. Estos datos indican la existencia de una extensa red metalúrgica de producción

Trab. Prehist., 73, N. ${ }^{\circ}$ 1, enero-junio 2016, pp. 160-179, ISSN: 0082-5638

doi: $10.3989 /$ tp.2016.12169 
y circulación de metal durante el II milenio cal BC (Soriano 2013: 155-157). Dado que gran parte de estos ya han sido expuestos nos limitaremos a esbozarlos (Fig. 7).

Las actividades extractivas de cobre, a cielo abierto, se llevan a cabo en varias minas de la cuenca del Montsant (Tarragona). Los indicios de explotación proceden de la Solana del Bepo (Ulldemolins) y de la Mina de la Turquesa (Cornudella de Montsant). La primera presenta unos ochenta útiles líticos de minero, en su mayoría picos con enmangue en forma de " $T$ ", y la segunda cerca de un centenar de herramientas, algunas con idénticas modificaciones. La mina de Barranc Fondo (Cornudella de Montsant) es otra potencialmente explotada (Montero-Ruiz et al. 2012). Según la caracterización mediante isótopos de plomo de estas explotaciones, el metal empleado en vasijas de reducción y objetos de cobre y bronce coincide con la de yacimientos cercanos. Estos datos, unidos a paralelos con otras minas europeas, apuntan hacia la datación de la Solana del Bepo en algún momento de la Edad del Bronce, mientras que el aprovechamiento de la Mina de la Turquesa se constata desde el Calcolítico y podría continuar después (Rafel et al. 2014; Rafel et al. 2016; Soriano et al. 2014).

La reducción de cobre se desarrolla en cuevas y abrigos de pequeñas dimensiones, todos ellos muy cercanos a las minas. Para todo el nordeste, y excluyendo las vasijas de reducción con contexto claro en el Calcolítico Reciente, contamos con ocho ejemplares sin contexto procedentes de cinco yacimientos (Calcolítico - Bronce Inicial): Coveta de l'Heura, Balma del Duc (dos ejemplares), Cova del Cartanyà (Vilaverd), Cova del Buldó (Rojals) y Cova Josefina (Escornalbou) (tres ejemplares) (Soriano 2013: 62-64). Estas cavidades permitían llevar a cabo, de forma intermitente o estacional, las actividades de reducción a resguardo de las inclemencias del tiempo. Su proximidad a las minas sería un argumento a favor de su sincronía. La cercanía entre áreas de extracción y de reducción, así como el empleo de cavidades para la segunda función se documenta durante el Bronce Antiguo - Medio en yacimientos del sur de Francia (Gattiglia y Rossi 1996; Barge 2003; Carozza et al. 2010).

Las labores de fundición se distribuyen por todo el nordeste y nunca se asocian con reducción o procesado de mineral, a pesar de la cercanía ocasional de menas metalíferas. La mayoría proceden de asentamientos en "agrupación de fosas" inequívocamente del Bronce Inicial, concentrados en el llano de Lleida (Minferri y Cantorella) y en zonas al norte (Can Roqueta y Can Mur) y sur de la Depresión Prelitoral catalana (Camp Cinzano y El Bordellet ${ }^{12}$ en Vilafranca del Penedès) (Soriano y Amorós 2014b). Otras evidencias sin contexto, ubicadas en el sudeste de la Depresión Central, se adscriben tipológicamente a este periodo (Soriano 2013: 70). Por último hay que citar la tumba del Forat de la Tuta (Riner, Lleida), recientemente reinterpretada como de metalúrgico, donde se recuperaron tres moldes y restos de mineral de cobre (Soriano 2011).

En los asentamientos con indicios de fundición se han documentado pocos o ningún objeto metálico relacionado con la distribución. Paralelamente la morfometría de varios objetos metálicos (hachas planas, hachas de rebordes, puñales) coincide con la de los moldes metalúrgicos donde, probablemente, se fundieron. Esta coincidencia conecta asentamientos separados, a veces, más de $150 \mathrm{~km}$ y refuerza la idea de que existió un sistema metalúrgico de circulación y/o distribución (Soriano 2013: 96-100; Soriano y Amorós 2014b).

Finalmente hay datos adicionales no metalúrgicos que respaldan lo expuesto hasta ahora. El reciente estudio de la industria lítica tallada de Minferri, así como del cercano asentamiento de Pla de Tabac I (Montoliu de Lleida), sin evidencias metalúrgicas pero con un objeto metálico, indican que una parte importante del sílex empleado procede de la cuenca del Montsant (Palomo et al. 2013; Esteve et al. 2015). Cabe pensar en un escenario donde la explotación del cobre y, quizás también del estaño, se vería acompañada de la recogida de sílex y del procesado in situ de estas materias (reducción del metal, talla lítica). Este proceso incluiría el aprovechamiento, entre otras, de madera como combustible y/o para el enmangue de los útiles mineros, sin excluir otros posibles recursos potenciales. El metal, una vez reducido y en forma de lingote o preforma, se

\footnotetext{
12 Segura, S. y Medina, E. 2015: Memòria de la intervenció arqueològica a les obres de construcció $i$ condicionament de l'Eix Diagonal (Carreteres C-15 y C-37). Tram 1. Vilanova $i$ la Geltrú-Canyelles-Vilafranca-Olèrdola-La Granada. Inédita, Servei d'Arqueologia i Paleontologia, Generalitat de Catalunya. Mataró.
} 
trasladaría a los centros metalúrgicos fundidores para la producción de objetos metálicos que luego serían distribuidos entre diversos asentamientos.

\subsection{Interacción e innovación tecnológica}

La metalurgia calcolítica y la del Bronce Inicial varían en la organización de la producción y en las propias características del proceso metalúrgico. En el primer periodo, y aunque los datos son escasos, el crisol de Bauma del Serrat del Pont, el único documentado, por sus pocas diferencias con las cerámicas comunes podría tratarse de un contenedor reutilizado (Alcalde et al. 1998). Tampoco se constatan moldes pero su empleo es indiscutible: los datos metalógráficos atestiguan el uso de estos, que quizás prodrían haberse fabricado mediante arena compacta y ser de tipo monovalvo abierto (Rovira y Gómez Ramos 2003; Ottaway y Wang 2004: 64). Como contrapartida durante el Bronce Inicial se introducen una serie de importantes innovaciones. Los crisoles se fabrican ex profeso. Pueden incluir elementos de prensión y/o piquera, que favorecen su manipulación y permiten un vertido más preciso, básico para los moldes de tipo monovalvo cerrado. Son la segunda novedad de este periodo y sirven para obtener útiles destinados a la percusión directa o indirecta (hachas, cinceles/ escoplos). El resto de artefactos (punzones, puntas de flecha, brazaletes) se producen en moldes de arena y, quizás, empleando crisoles sin sistema de prensión (Soriano 2013: 71). La tercera innovación es la aparición y uso mayoritario y/o exclusivo del bronce en útiles y ornamentos, con una proporción de estaño relativamente elevada (entre 6-15\%) (Rovira et al. 1997; Soriano 2013: anexo 3). Esta situación, compartida con el Valle del Ebro (Fernández-Miranda et al. 1995; Rodríguez de la Esperanza 2005: 69-70), se da incluso en los momentos más antiguos y es una diferencia remarcable respecto a los restantes grupos peninsulares, que emplean cobre puro.

Las novedades acontecidas en este período carecen de precedentes en el Calcolítico que justifiquen un descubrimiento autónomo e independiente. Algunas de ellas requerirían de un proceso previo, no detectado, de conocimiento y experimentación. La ausencia de tales evidencias y la confluencia de varias innovaciones tecnológicas en un mismo momento sugieren una transferencia de conocimiento. Contamos con datos cronológicos y tipológicos que conectan el nordeste con el Valle del Ebro y el norte de Italia, regiones que, a nuestro entender, aportan explicaciones para afrontar esta cuestión. Los primeros nexos detectados son con los grupos de Polada y, posteriormente, con los de las Terramaras. Como hemos expuesto, los principales paralelos para los crisoles con sistema de prensión proceden del Egeo, norte de Italia y ciertas islas del Mediterráneo Occidental (Córcega, Cerdeña). Recientemente en estos mismos territorios, y en similar cronología, han sido localizados moldes para puñales análogos al ejemplar de Camp Cinzano, un tipo de molde con escasos paralelos en la Península Ibérica (Soriano y Amorós 2014b). Del mismo modo, tres grupos de objetos metálicos muestran similitudes destacables con dicha región (Soriano 2013: $155-$ 160). El primero son las hachas de rebordes. En la Península Ibérica solo se localizan al norte del Ebro y se documentan por vez primera en los grupos calcolíticos de Remedello y Rinaldone (c. 3300-2400 cal BC) y, posteriormente, a lo largo de la Edad del Bronce en el norte de Italia, Francia y Europa Central. El segundo es una aguja de bronce con cabeza discoidal decorada (Cova del Toll), cuyos paralelos más cercanos están en Polada. El tercero es una punta de flecha de tipo cónico pedunculado (Cova d'Aigües Vives), con ejemplares similares en las Terramaras y, sobre hueso, tanto en el nordeste como en el Valle del Ebro. Por último un tipo cerámico tan característico de los grupos de Polada como los vasos con asa de apéndice de botón se localiza en la Península Ibérica únicamente en el nordeste, escaseando en el Valle del Ebro (Espejo 2000-2001).

El origen de la metalurgia del bronce es una conexión que se añade a las expuestas. Dejando de lado la producción accidental de bronce en contexto campaniforme de Bauma del Serrat del Pont (c. 2750-2600 cal BC) (Alcalde et al. 1998: 92-97), hay objetos de gran antigüedad en la Submeseta Norte, como los dos punzones de Cueva Maja (Cabrejas del Pinar, Soria, c. $2100 \mathrm{cal}$ BC) (Samaniego Bordiu et al. 2001: 85-87). En Galicia y norte de Portugal se conocen casos similares aunque los primeros indicios de producción no remontan más allá de c. 1750 cal $\mathrm{BC}$, según muestra A Sola (Braga) y Fraga dos Corvos (TrasOs-Montes) (Senna-Martínez 2007; Comendador-

Trab. Prehist., 73, N. ${ }^{\circ}$ 1, enero-junio 2016, pp. 160-179, ISSN: 0082-5638

doi: 10.3989/tp.2016.12169 
Rey et al. 2008; Senna-Martínez et al. 2011). En el suroeste los primeros objetos se sitúan c. 1650 cal BC en Torre Velha 3 (Serpa, Portugal) (Valério et al. 2014). En el área argárica un bronce pobre aparece c. 1900 cal BC (Montero Fenollós et al. 2014) y hacia c 1750 cal BC los bronces normalizados en torno al $8-12 \%$ de estaño. Ambos convivirán de forma minoritaria con el cobre arsenical hasta c. 1550 cal BC, cuando se generalizan (Lull et al. 2010: 327). Todo apunta a que la introducción del bronce en la Península Ibérica fue un proceso complejo y diverso donde, probablemente, intervinieron diversos factores y grupos arqueológicos. Las primeras evidencias de su producción y generalización se localizan sin ninguna duda en el nordeste y en el Valle del Ebro, en los yacimientos de Minferri (c. 2000-1800 cal BC) y Monte Aguilar (Bárdenas Reales, Navarra) (c. 1850-1800 cal BC) (Sesma y García 1993-1994). En el resto de Europa las regiones más cercanas con bronce son el norte de Italia (grupos de Remedello, Rinaldone y, posteriormente, Polada) y oeste de Francia (Túmulos Armoricanos) (Roberts 2014: 434; Valério et al. 2014: 69). En su mitad sur se conocen objetos aislados en yacimientos de Mediodía Pirineos y Aquitania (Fernández-Miranda et al. 1995: 60-62). Las interacciones entre el sur de Francia y el nordeste -Valle del Ebro están constatadas en ciertos tipos cerámicos (epicampaniforme de tipo barbelé) y óseos (botones prismáticos triangulares de perforación en "V") (Uscatescu 1992: 74-83; Lemercier et al. 2007). Es, pues, plausible que la metalurgia del bronce, que se introdujo en el nordeste a través de tierras francesas por las mismas vías de transmisión que la cerámica y los objetos metálicos, se originara en el norte de Italia.

\section{CONCLUSIONES Y VALORACIÓN}

Los crisoles con sistema de prensión de Can Mur, Can Roqueta II (Rovira Hortalà et al. 2007), Minferri ${ }^{13}$ y Cantorella (Escala et al. 2014) son útiles metalúrgicos con un elevado grado de desarrollo tecnológico. Estos coinciden con otras innovaciones surgidas en la producción metalúrgica

\footnotetext{
13 Véase n. 8.
}

durante el Bronce Inicial, como son la aparición de moldes de piedra de tipo monovalvo cerrado y el empleo generalizado de bronce. Dichos útiles se contextualizan en una producción fuertemente segmentada e interdependiente entre asentamientos, vinculados cada uno y de forma excluyente con una fase de la producción metalúrgica. La distancia, a menudo elevada, entre ellos así como la constatación de la circulación de productos metálicos por todo el territorio demuestra la existencia de una extensa red metalúrgica durante el II milenio cal BC.

Los paralelos constatados para este tipo de crisoles y otros útiles metalúrgicos (un molde para puñales) y objetos metálicos (veinticuatro hachas de rebordes, una aguja de cabeza discoidal, una punta de flecha cónica pedunculada) se sitúan inequívocamente en el norte de Italia, vinculados con los grupos de Polada (2200-1600 cal BC) y, posteriormente, las Terramaras (c. 1600-1325 cal $\mathrm{BC})$. Sin embargo recordemos que los crisoles morfológicamente más similares (tipo con base engrosada y perforación, procedentes de Castellaro del Vhò y Montale) pertenecen ya a las Terramaras. Es decir, son más tardíos que los ejemplares del nordeste (Marzatico 1997; Cierny et al. 2002). De esta manera consideramos que en esta región debe situarse el origen de gran parte de las innovaciones metalúrgicas expuestas. A pesar de ello no podemos desdeñar que zonas como el sur de Francia y ciertas islas del Mediterráneo Occidental (Cerdeña, Córcega) hubieran desempeñado un papel que iría más allá del de meras zonas de paso. En la actualidad carecemos de datos suficientes para proponer un área única de dispersión para este tipo de crisoles. Posteriormente y desde el nordeste, algunas de estas innovaciones habrían alcanzado el Levante (crisoles de Peña la Dueña, molde de Mola Alta de Serelles), gracias a unos intercambios fluidos entre ambas regiones en otros ámbitos de la cultura material (Soriano y Amorós 2014b). Puede que una parte del Valle del Ebro recibiera influencias similares a las del nordeste, con la llegada de la metalurgia del bronce (Navarra) o de las hachas de rebordes (Huesca, Zaragoza). Sin embargo, y a la vista de las abrumadoras similitudes registradas entre ambas regiones (Soriano y Amorós 2014a), tampoco podemos descartar una transferencia indirecta a través del nordeste. Esperemos que trabajos posteriores permitan arrojar más luz sobre estas cuestiones. 


\section{AGRADECIMIENTOS}

A Ignacio Montero (CCHS-CSIC) por su colaboración y soporte técnico. A Joan B. López y Andreu Moya (Universitat de Lleida), James D. Muhly (University of Pennsylvania), Mark Pearce (University of Nottingham), Andrea Dolfini (Newcastle University), Cécile Oberweiler (UMR 7041, Université Paris 1 Panthéon-Sorbonne), Gustau Aguilella (Diputación de Castellón), Xavier Esteve (SERP, Universitat de Barcelona) y Sergio Segura, Esther Medina y Francesc X. Florensa (ATICS Gestió i difusió del patrimoni arqueològic i històric) por la información proporcionada. Andreu Mur, depositario de los materiales, nos facilitó generosamente la realización de este estudio. A los dos evaluadores anónimos por la revisión y comentarios.

\section{BIBLIOGRAFÍA}

Alcalde, G.; Molist, M.; Montero, I.; Planagumà, L1.; Saña, M. y Toledo, A. 1998: "Producciones metalúrgicas en el nordeste de la Península Ibérica durante el III milenio cal. AC: El taller de la Bauma del Serrat del Pont (Tortellà, Girona)". Trabajos de Prehistoria 55 (1): 81-100.

Alcocer Grau, J. 1945: "Dos estaciones argáricas de la Región Levantina". Archivo de Prehistoria Levantina 2: 151-163.

Barge, H. 2003: Saint-Véran, la montagne, le cuivre et l’homme. Société Actilia Multimédia. Theix.

Battaglia, R. 1943: "La palafitta del Lago di Ledro nel Trentino". Memorie del Museo di Storia Naturale della Venezia Tridentina 7: 3-63.

Betancourt, P. P. y Muhly, J. D. 2007: "The crucibles of the Aghia Photia Cemetery". En P. M. Day Y R. C. P. Doonan (eds.): Metallurgy in the Early Bronze Age Aegean. Oxbow Books, Sheffield Studies in Aegean Archaeology. Sheffield: 146-153.

Blitzer, H. 1995: "Minoan implements and industries". En J. W. Shaw y M. C. Shaw (eds.): Kommos I. The Kommos Region and Houses of the Minoan Town. Part 1: The Kommos Region, Ecology, and Minoan Industries. Princeton University Press. Princeton: 403-536.

Camps, G. (ed.) 1988: Terrina et le Terrinien. Recherches sur le Chalcolithique de la Corse. Collection de l'École Française de Rome 109. Roma.

Camps, G. 1990-1991: "Les creusets de Terrina (Aléria, Haute-Corse)". En Colloque International Hommage au Dr. Jean Arnal. Le Chalcolithique en Languedoc. Archéologie en Languedoc 15: 41-49.
Carlús, X.; López Cachero, J.; Oliva, M.; Palomo, T.; Rodríguez, A.; Terrats, N.; Lara, C. y Villena, N. (eds.) 2007: Cabanes, sitges $i$ tombes. El paratge de Can Roqueta (Sabadell, Vallès Occidental) del 1300 al 500 ANE. Quaderns d'Arqueologia 4, Museu d'Història de Sabadell. Sabadell.

Carlús, X.; López Cachero, J.; Terrats, N.; Oliva, M.; Palomo, T. y Rodríguez, A. 2008: "Diacronia durant la prehistòria recent a Can Roqueta (SabadellBarberà del Vallès, Vallès Occidental) entre el VI i el I mil·lenni cal ANE”. Cypsela 17: 115-142.

Carozza, L. y Ambert, P. 1996: "Origine et développement de la première métallurgie française: état de la question". Archéologie en Languedoc 20,1: 43-56.

Carozza, L. ; Rostan, P. ; Bourgarit, D. ; Mille, B. ; Coquinot, Y. ; Burens, A. y Escanilla Artigas, N. 2010: 'Un site métallurgique du Bronze ancien dans le vallon du Longet à Molines-en-Queyras (Hautes-Alpes): caractérisation du contexte archéologique et des déchets liés aux activités de métallurgie extractive". En S. Tzortzis y X. Delestre (eds.): Archéologie de la Montagne Européenne, actes de la table ronde internationale (Gap 2008). Bibliothèque d'archéologie méditerranéenne et africaine 4, Errance. Paris: 261-281.

Cierny, J.; Degasperi, N. y Frontini, P. 2002: “Castellaro del Vhò di Piadena (Cremona): strutture a cielo aperto del Bronze Medio". En A. Giumlia-Mair (ed.): I Bronzi Antichi: produzione e tecnologia. Atti del XV Congresso Internazionale sui bronzi antichi (Grado-Aquilieia 2001). Monographies Instrumentum 21, Mergoil. Autun: 44-51.

Coghlan, H. H. 1975: Notes on the Prehistoric Metallurgy of Copper and Bronze in the Old World. Occasional Papers on Technology 4, Pitt Rivers Museum. Oxford.

Comendador-Rey, B.; Reboreda-Morillo, S.; Kockelmann, W.; Macdonald, M. y Pantos, M. 2008: "Early Bronze Technology at Land's End, North Western Iberia". En S. A. Paipetis (ed.): Science and Technology in Homeric Epics. History of Mechanism and Machine Science 8, Springer Netherlands: 113-131.

Dungworth, D. 2000: "A note on the analysis of crucibles and moulds". Historical Metallurgy 34, 2: 83-86.

Equip Minferri 1997: "Noves dades per a la caracterització dels assentaments a l'aire lliure durant $\mathrm{La}$ primera meitat del II mil·lenni cal. BC: primers resultats de les excavacions en el jaciment de Minferri (Juneda, les Garrigues)". Revista d'Arqueologia de Ponent 7: 161-211.

Escala, O.; Moya, A.; Tartera, E.; Vidal, A. y Armentano, N. 2014: "Cantorella (Maldà, Urgell), un nou assentament a l'aire lliure del neolític final-calcolític i del bronze ple a la vall del Corb". Tribuna d'Arqueologia 2011-2012: 129-172.

Espejo, J. M. 2000-2001: "La cerámica con asas de apéndice de botón: un estado de la cuestión". Pyrenae 31-32: 29-55. 
Esteve, X.; Armentano, N.; Espejo, J. M.; Gallart, J.; Gibaja, J. F.; López, D.; Mangado, X.; Marín, D.; Nadal, J.; Oms, F. X.; Orri, E.; Sánchez, M. y Vila, S. 2015: "El Pla de Tabac I (Montoliu de Lleida), un assentament de l'edat del bronze a la Plana de Lleida". Revista d'Arqueologia de Ponent 25: 137-168.

Fasnacht, W. 1991: "Analyses d'objets en cuivre du Néolithique Récent du bassin zürichois". En J. P. Mohen y C. Éluère (eds.): Découverte du métal. Picard, Millénaires 2. París: 157-166.

Fernández-Miranda, M.; Montero, I. y Rovira, S. 1995: "Los primeros objetos de bronce en el Occidente de Europa". Trabajos de Prehistoria 52 (1): 57-69.

Freestone, I. C. 1989: "Refractory materials and their procurement". En A. Hauptmann, E. Pernicka y G. A. Wagner (eds.): Old World Archaeometallurgy. Proceedings of the International Symposium (Heildeberg 1987) 7: 155-162. Bochum.

Garenne-Marot, L. 1985: "Le travail du cuivre dans l'Égypte pharaonique d'après les peintures et les bas-reliefs". Paléorient 11,1: 85-100.

Gattiglia, A. y Rossi, M. 1995: "Les céramiques de la mine préhistorique de Saint-Véran (Hautes-Alpes)". Bulletin de la Société Préhistorique Française 92: 509-518.

GIP - Grup d'Investigació Prehistòrica 2002: Els colors de la Terra. La vida y la mort en una aldea d'ara fa 4000 anys. Minferri, Juneda. Quaderns de la Sala d'Arqueologia 1. Lleida.

Kearns, Th.; Martinón-Torres, M. y Rehren, Th. 2010: "Metal to mould: alloy identification in experimental casting moulds using XRF". Historical Metallurgy 44,1: 48-58.

Lemercier, O.; Leonini, V.; Tramoni, P. y Furestier, R. 2007: "Campaniformes insulaires et continentaux de France et d'Italie méditerranéennes. Relations et échanges entre Corse, Sardaigne, Toscane et Midi français dans la seconde moitié du troisième millénaire avant notre ère'. En A. D'Anna, J. Cesari, L. Ogel y J. Vaquer (eds.): Corse et Sardaigne préhistoriques: relations et échanges dans le contexte méditerranéen. 128e Congrès National des Sociétés Historiques et Scientifiques (Bastia 2003). Comité des travaux historiques et scientifiques. Paris: 241-252.

Lo Schiavo, L. 2005: "Pre-nuragic metallurgy records". En L. Lo Schiavo, A. Giumlia-Mair, U. Sanna y R. Valera (eds.): Archaeometallurgy in Sardinia from the origins to the beginning of the Early Iron Age. Monographies Instrumentum 30, Monique Mergoil Montagnac. Millau: 257-278.

Lull, V.; Micó, R.; Rihuete Herrada, C. y Risch, R. 2010: "Metal and social relations of production In the $3^{\text {rd }}$ and $2^{\text {nd }}$ millennia $\mathrm{BCE}$ in the Southeast of the Iberian Peninsula". Trabajos de Prehistoria 67(2): 323-347.

Martín, A.; Gallart, J.; Rovira Hortalà, Mª C. y MataPerelló, J. M. 1999: "Nordeste". En G. Delibes e I. Montero (coords.): Las primeras etapas metalúr- gicas de la Península Ibérica II. Estudios regionales. Instituto Universitario Ortega y Gasset. Madrid: 115-177.

Marzatico, F. 1997: "L'industria metallurgica nel Trentino durante l'età del bronzo". En M. Bernabò Brea, A. Cardarelli y M. Cremaschi (eds.): Le Terramare. La più antica civilità padana. Electa. Milano: 570-591.

Montero, I. 1999: "Sureste". En G. Delibes e I. Montero (eds.): Las primeras etapas metalúrgicas de la Península Ibérica II. Estudios regionales. Instituto Universitario Ortega y Gasset. Madrid: 323-357.

Montero-Ruiz, I.; Rafel, N.; Hunt, M.; Mata-Perelló, J. $\mathrm{M}^{\mathrm{a}}$.; Odriozola, C. P.; Soriano, I. y Murillo-Barroso, M. 2012: "Minería prehistórica en el Priorato. Caracterización arqueométrica de minas de Cornudella y Ulldemolins". En J. M. ${ }^{\text {a }}$ Mata-Perelló (ed.): El patrimonio minero y metalúrgico a lo largo de la Historia. Libro de actas del VII Congreso Internacional sobre Minería y Metalurgia Históricas en el Sudoeste Europeo (Utrillas 2012): 131-140. Utrillas.

Montero Fenollós, J. L.; Martínez Rodríguez, A. y Ponce García, J. 2014: "Nuevos datos sobre la metalurgia argárica en Lorca”. Alberca 12: 7-24.

Nieto Espinet, A.; Moya I Garra, A.; López Melcion, J. B. y Agustí Farjas, B. 2014: "Ofrenes o deixalles? El cas dels bovins (Bos taurus) en context funerari del jaciment del bronze ple de Minferri (Lleida, Catalunya)". En A. Gardeisen y Ch. Chandezon (eds.): Equidés et bovidés de la Méditerranée antique. Rites et combats. Jeux et savoirs. Association pour le Développement de l'Archéologie en LanguedocRoussillon. Lattes: 53-111.

Oberweiler, C. 2011: "Les techniques de fonderie en Crète minoenne et mycénienne. I. Les outils Du Fondeur". Bulletin du Correspondance Hellénique 135: 421-491.

Ottaway, B. S. y Wang, Q. 2004: Casting experiments and microstructure of archaeological relevant bronzes. British Archaeological Reports, International Series 1331, Archaeopress. Oxford.

Palomar Macian, V. 1995: La Edad del Bronce en el Alto Palancia. Ayuntamiento de Segorbe. Segorbe.

Palomo, A.; Gibaja, J. F.; Ortega, D.; Alonso, N.; Marín, D. y Moya, A. 2013: "La industria lítica tallada del asentamiento de Minferri (Juneda, Lleida), a finales del III/primer mitad del II milenio cal BC'. Cypsela 19: 261-280.

Palomo, A. y Rodríguez, A. 2004: “Can Roqueta II (Sabadell, Vallès Occidental)". Tribuna d'Arqueologia 2000-2001: 77-97.

Pearce, M. 2013: "The absolute chronology of site IV at Terrina (Aléria, Haute-Corse) and early metallurgy on Corsica and Sardinia". Accordia Research Papers 12: 41-55.

Peche-Quilichini, K. 2007: "Les fouilles Grosjean à Alo-Bisughjè (Bilia, Corse-du-Sud). Le mobilier céramique". Bulletin de la Société des Sciences Historiques et Naturelles de la Corse 718-719: 1-29. 
Peche-Quilichini, K. 2014: “Sous le tesson, l'alliage. Note morphologique et chronologique sur les creusets de l'âge du bronze en Corse". Bulletin de l'Association pour la Promotion des Recherches sur l'Age du Bronze 12: 129-133.

Perini, R. 1987: Scavi archeologici nella zona palafitticola di Fiavè-Carera. Parte II. Campagne 19691976. Resti della cultura materiale. Metallo- ossolegno. Patrimonio Storico e Artístico del Trentino 9. Trento.

Rafel, N.; Montero-Ruiz, I.; Soriano, I. y DelgadoRaack, S. 2016: "L'activité minière préhistorique dans le Nord-Est de la péninsule Ibérique. Étude sur la Coveta de l'Heura et l'exploitation du cuivre à la Solana del Bepo (Tarragone, Espagne)". Bulletin de la Société Préhistorique Française 113 (1): 95-129.

Rafel, N.; Montero-Ruiz, I.; Soriano, I.; Hunt, M. y Armada, X-L. 2014: "Nuevos datos sobre la minería pre y protohistórica en Cataluña". Cuadernos de Prehistoria y Arqueología de la Universidad de Granada 24: 147-166.

Rageth, J. 1974: "Der Lago di Ledro im Trentino und seine Beziehungen zu den alpinen und mittel-europäischen Kulturen”. Bericht der Römisch-Germanischen Kommission 55: 73-259.

Reimer, P. J.; Bard, E.; Bayliss, A.; Beck, J. W.; Blackwell, P. G.; Bronk Ramsey, C.; Buck, C. E.; Cheng, H.; Edwards, R. L.; Friedrich, M.; Grootes, P. M.; Guilderson, T. P.; Haflidason, H.; Hajdas, I.; Hatté, C.; Heaton, T. J.; Hogg, A. G.; Hughen, K. A.; Kaiser, K. F.; Kromer, B.; Manning, S. W.; Niu, M.; Reimer, R. W.; Richards, D. A., Scott, E. M.; Southon, J. R.; Turney, C. S. M. y van der Plicht, J. 2013: "IntCal13 and MARINE13 radiocarbon age calibration curves 0-50000 years cal BP". Radiocarbon 55.4: 1869-1887.

Roberts, B. W. 2014: "Production networks and consumer choice in the earliest metal of Western Europe". En B. W. Roberts y Ch. P. Thornton (eds.): Archaeometallurgy in Global Perspective, Methods and Syntheses. Springer. New York: 423-446.

Rodríguez de la Esperanza, M. ${ }^{a}$ J. 2005: Metalurgia y metalúrgicos en el Valle del Ebro (c. 2900-1500 cal. A.C.). Biblioteca Archaeologica Hispana 24, Real Academia de la Historia e Institución "Fernando el Católico". Madrid.

Roussot-Larroque, J. 1997: "La Lède du Gurp et la métallurgie du Bronze moyen dans le Médoc". Revue Archéologique de Bordeaux 88: 33-56.

Roussot-Larroque, J. 2007: "Le temps qui passe et le temps qui'l fait: prises et déprises agricoles en Médoc durant l'âge du Bronze". En H. Richard, M. Magny y C. Mordant (eds.): Environnements et cultures à l'âge du Bronze en Europe occidentale. Documents préhistoriques 21: 285-293.

Rovira, S. y Gómez Ramos, P. 2003: Las primeras etapas metalúrgicas en la Península Ibérica. III. Estudios metalográficos. Autores. Madrid.
Rovira, S.; Montero, I. y Consuegra, S. 1997: Las primeras etapas metalúrgicas de la Península Ibérica I. Análisis de materiales. Instituto Universitario Ortega y Gasset. Madrid.

Rovira Hortalà, M. ${ }^{\text {a C } .1998: ~ “ A c t i v i t e ́ s ~ m e ́ t a l l u r g i s t e s ~ a ̀ ~}$ l'extrême nord-est de la Péninsule Ibérique pendant l'Age du Bronze Ancien-Moyen. Le site de Minferri (Lleida)". En C. Mordant, M. Pernot y V. Rychner (eds.): L'atelier du bronzier en Europe du XX au VIII siècle avant notre ère. Actes du colloque international Bronze'96 Neuchâtel et Dijon, II: Production, circulation et consommation du bronze. Comité des travaux historiques et scientifiques. Paris: 241-248.

Rovira Hortalà, M. ${ }^{a}$ C. 2006: "El Bronze Inicial a Catalunya des de la perspectiva metal·lúrgica”. Cypsela 16: $135-145$.

Rovira, M. ${ }^{\text {a }}$ C.; Palomo, A. y Rodríguez, A. 2007: "Metalurgia prehistórica en la Catalunya prelitoral: los instrumentos de broncista de Can Roqueta II (Sabadell, Barcelona)". En J. M. Mata-Perelló (ed.): Actas del I Congreso Internacional de Minería y Metalurgia en el contexto de la Historia de la Humanidad: Pasado, presente y futuro. IV Simposio sobre Minería y Metalurgia Históricas del Suroeste Europeo (Mequinenza 2006): 505-510. Mequinenza.

Samaniego Bordiu, B.; Jimeno Martínez, A.; Fernández Moreno, J. J. y Gómez Barrera, J. A. 2001: Cueva Maja (Cabrejas del Pinar, Soria): Espacio y simbolismo en los inicios de la Edad del Bronce. Memorias 10, Arqueología en Castilla y León. Junta de Castilla y León. Valladolid.

Senna-Martínez, J. C. 2007: "Aspectos e problemas das origens e desenvolvimento da metalurgia do bronze na Fachada Atlântica peninsular". Estudos Arqueológicos de Oeiras 15: 119-134.

Senna-Martínez, J. C.; Luís, E.; Araújo, M. de F.; Silva, R.; Fingueiredo, E. y Valério, P. 2011: "First Bronzes of North-West Iberia: the data from Fraga dos Corvos habitat site". En C. M. Braz Martins, A. M. S. Bettencourt, J. I. F. P. Martins y J. Carvalho (eds.): Povoamento e Exploração dos Recursos Mineiros na Europa Atlântica Ocidental. Centro de Investigação Transdisciplinar Cultura, Espaço e Memória, Associação Portuguesa para o Estudio do Quaternário. Braga: 377-390.

Sesma, J. y García, M. a L. 1993-1994: "Monte Aguilar (Bárdenas Reales de Navarra). Campañas de 1990-1991". Trabajos de Arqueología de Navarra 11: $276-280$.

Simón, J. L. 1998: La metalurgia prehistórica valenciana. Servicio de Investigación Prehistórica, Serie de Trabajos Varios 93. Valencia.

Soriano, I. 2011: "De tumbas de metalúrgico en el Nordeste peninsular. El Forat de la Tuta (Riner, Solsonès, Lleida)". Revista d'Arqueologia de Ponent 21: 37-56.

Soriano, I. 2013: Metalurgia y Sociedad en el Nordeste de la Península Ibérica (finales del IV - II milenio

Trab. Prehist., 73, N. ${ }^{\circ}$ 1, enero-junio 2016, pp. 160-179, ISSN: 0082-5638

doi: $10.3989 /$ tp.2016.12169 
cal ANE). British Archaeological Reports, International Series 2502, Archaeopress. Oxford.

Soriano, I. y Amorós, J. 2014a: "El vaso geminado de Camp Cinzano (Vilafranca del Penedès, Barcelona) y las relaciones nordeste - levante - Valle del Ebro durante la Edad del Bronce". Revista d'Arqueologia de Ponent 24: 9-25.

Soriano, I. y Amorós, J. 2014b: "Moldes para puñales en la Península Ibérica durante la Edad del Bronce. El caso de Camp Cinzano (Vilafranca del Penedès, Alt Penedès, Barcelona)". Trabajos de Prehistoria 71 (2): 368-385.

Soriano, I.; Rafel, N. y Hunt Ortiz, M. A. 2014: “Una nueva explotación minera prehistórica en el nordeste: la Mina de la Turquesa o del Mas de les Moreres en Tarragona". VIII Congreso Internacional sobre Minería y Metalurgia antiguas en el Sudoeste Europeo (Granada 2014): 13-16. http://www.sedpgym.
es/descargas/libros_actas/GRANADA_2014/preactas-granada-2014.pdf (consulta 11-II-2016).

Thornton, Ch. P. 2014: "The emergence of complex metallurgy on the Iranian Plateau". En B. W. Roberts y Ch. P. Thornton (eds.): Archaeometallurgy in Global Perspective, Methods and Syntheses. Springer. New York: 665-696.

Tylecote, R. F. 1976: A History of Metallurgy. The Metals Society. London.

Uscatescu, A. 1992: Los botones de perforación en "V" en la Península Ibérica y las Baleares durante la Edad de los Metales. Foro Arqueología. Madrid.

Valério, P.; Monge Soares, A. M.; Araújo, M. F.; Silva, R. J. C.; Porfirio, E. y Serra, M. 2014: "Arsenical copper and bronze in Middle Bronze Age burial sites of southern Portugal: the first bronzes in Soutwestern Iberia". Journal of Archaeological Science 42,1: $68-80$. 